\title{
Integrin-Mediated Regulation of Synaptic Morphology, Transmission, and Plasticity
}

\author{
Jeffrey Rohrbough, ${ }^{1}$ Michael S. Grotewiel, ${ }^{2}$ Ronald L. Davis, ${ }^{3}$ and Kendal Broadie ${ }^{1}$ \\ 1Department of Biology, University of Utah, Salt Lake City, Utah 84112, '2Department of Zoology, Michigan State University, \\ East Lansing, Michigan 48824-1312, and ${ }^{3}$ Department of Cell Biology and Department of Psychiatry and Behavioral \\ Sciences, Baylor College of Medicine, Houston, Texas 77030
}

\begin{abstract}
Volado, the gene encoding the Drosophila $\alpha$ PS3-integrin, is required for normal short-term memory formation (Grotewiel et al., 1998), supporting a role for integrins in synaptic modulation mechanisms. We show that the Volado protein (VOL) is localized to central and peripheral larval Drosophila synapses. VOL is strongly concentrated in a subpopulation of synaptic boutons in the CNS neuropil and to a variable subset of synaptic boutons at neuromuscular junctions (NMJs). Mutant morphological and functional synaptic phenotypes were analyzed at the NMJ. Volado mutant synaptic arbors are structurally enlarged, suggesting VOL negatively regulates developmental synaptic sprouting and growth. Mutant NMJs exhibit abnormally large evoked synaptic currents and reduced $\mathrm{Ca}^{2+}$ dependence of transmission. Strikingly, multiple forms of $\mathrm{Ca}^{2+}-$ and activity-
\end{abstract}

dependent synaptic plasticity are reduced or absent. Conditional Volado expression in mutant larvae largely rescues normal transmission and plasticity. Pharmacologicially disrupting integrin function at normal NMJs phenocopies features of mutant transmission and plasticity within 30-60 min, demonstrating that integrins acutely regulate functional transmission. Our results provide direct evidence that Volado regulates functional synaptic plasticity processes and support recent findings implicating integrins in rapid changes in synaptic efficacy and in memory formation.

Key words: integrins; synaptic plasticity; synaptic signaling; adhesion; learning and memory; neuromuscular junction; Drosophila
A recent screen in Drosophila for new learning and memory mutants (Grotewiel et al., 1998) added a particularly intriguing new gene, Volado, to the growing list of genes involved in various phases of the learning-to-memory process (Boynton and Tully, 1992; Davis et al., 1995; Davis, 1996; Skoulakis and Davis, 1996; Dubnau and Tully, 1998). Volado, also known as $\alpha$ PS3 (Stark et al., 1997), encodes two $\alpha$-integrin proteins differing only in their first 63 amino acids (Stark et al., 1997; Grotewiel et al., 1998). The Volado (VOL) proteins have enriched expression in the adult mushroom bodies (Grotewiel et al., 1998), synapse-dense brain structures that serve as insect olfactory memory centers and have long been implicated in cAMP signaling-dependent forms of behavioral learning and memory (Davis et al., 1995; Davis, 1996; Dubnau and Tully, 1998). Viable Volado mutants have a dominant effect on adult olfactory memory, reducing short-term memory (STM) assessed 3-15 min after training by $\sim 50 \%$. The mutant STM defect is reversibly rescued by conditional VOL expression just $3 \mathrm{hr}$ before training (Grotewiel et al., 1998), suggesting a dynamic role for integrins in behavior modulation. These results indicate an exciting new potential role for integrins in mediating persistent changes in synaptic efficacy thought to accompany memory formation.

Integrins function as $\alpha \beta$ receptor heterodimers capable of interacting with a variety of extracellular matrix (ECM) and cytoskeletal proteins, mediating cell-cell and cell-ECM adhesion interactions and bidirectional signaling across cell membranes (Hynes, 1992; Diamond and Springer, 1994; Clarke and Brugge, 1995;

Received Feb. 15, 2000; revised June 29, 2000; accepted June 30, 2000.

This work was supported by a National Science Foundation CAREER grant, National Institutes of Health Grant GM54544, a Searle Scholar Award, and a Young Investigator Award from the Office of Naval Research (K.B.), and by National Institutes of Health Grant NS19904 and the R.P. Doherty-Welch Chair in Science (R.L.D.).We are grateful to K. Zinsmaier and V. Budnik for providing antibodies to CSP and DLG, respectively; to Y. Zhang for Syt-GFP and Syb-GFP flies; to E. Rushton for expert technical assistance; and to E. Jorgensen and members of the Broadie lab for critical comments on this manuscript.

Correspondence should be addressed to Kendal Broadie, Department of Biology, University of Utah, 257 South 1450 East, Salt Lake City, UT 84112. E-mail: broadie@biology.utah.edu.

Copyright (C) 2000 Society for Neuroscience $0270-6474 / 00 / 206868-11 \$ 15.00 / 0$
Jones, 1996). Cellular studies using peptide inhibitors of integrinECM ligand interactions have recently implicated synaptic integrins in rapid (minutes) and reversible consolidation of long-term potentiation (LTP) in the mammalian hippocampus (Bahr et al., 1997; Staubli et al., 1998), providing evidence that integrins function in long-term physiological plasticity related to learning. Dynamic changes in integrin-dependent adhesive interactions or intracellular signaling activity could mediate alterations in synapse morphology or number, or modulate transmission strength at existing synapses. Synaptic integrins are thus strategically positioned to have roles in both morphological and functional synaptic plasticity mechanisms used in memory formation and stabilization.

To test these models of integrin synaptic function, we have investigated the role of VOL at the Drosophila neuromuscular junction (NMJ), where previous studies have suggested a conserved mechanistic link with plasticity properties of central synapses (Zhong and Wu, 1991; Z hong et al., 1992; Wang et al., 1994; Broadie et al., 1997; Rohrbough et al., 1999). We examine an allelic series of Volado mutants to assess the role of VOL in regulating synaptic terminal morphology, functional transmission, and plasticity properties, and demonstrate that mutant defects can be conditionally rescued by expression of a Volado transgene. We complement this genetic approach by acutely inhibiting normal integrin function with a peptide containing the Arg-Gly-Asp consensus sequence common to many integrin-binding ECM ligands (Chen and Grinnell, 1995, 1997; Bahr et al., 1997; Baneres et al., 1998; Graner et al., 1998; Staubli et al., 1998). Our results suggest that VOL may actively regulate both synaptic architecture and functional transmission properties.

\section{MATERIALS AND METHODS}

Drosophila mutant and transgenic stocks. Analysis of the Volado gene structure and transcripts, and construction and analysis of the viable P-element insertion allele $\left(V_{o l}{ }^{1} ; r y\right)$ and viable excision allele $\left(V o l^{2} ; r y\right)$, were described previously (Grotewiel et al., 1998). The same $\alpha$-integrin subunit gene, designated $\alpha \mathrm{PS} 3$, and transcripts were identified in an independent study (Stark et al., 1997); this study also indicated that $\alpha$ PS3/ Volado is allelic to scab, previously identified as a dorsal closure mutant (Nusslein-Volhard et al., 1984). Two additional putative $\alpha$-integrins with 
homology to $\alpha \mathrm{PS} 3$ (currently designated $\alpha \mathrm{PS} 4$ and $\alpha \mathrm{PS} 5$ ) have also recently been identified in the Drosophila genome (FlyBase, 2000).

The Volado locus is organized into two transcription units, Vol-long (Vol-1) and $\mathrm{Vol}$-short ( $\mathrm{Vol}$-s), encoding RNAs of 4.6 and $4.4 \mathrm{~kb}$, respectively (Stark et al., 1997; Grotewiel et al., 1998). The VOL $\alpha$-integrin proteins (VOL-l and VOL-s) encoded by these transcripts consist of identical 1115 amino acids sequences except for their first 63 amino acids (Grotewiel et al., 1998). The $\operatorname{Vol}^{1} \mathrm{P}$-element carrying the $r y^{+}$reporter gene is located in intron 1 of the $\mathrm{Vol}-1$ transcript. $\mathrm{Vol}^{2}$ deletes $816 \mathrm{bp}$ spanning exon 1 of the $\mathrm{Vol}$-s transcript. The homozygous $\mathrm{Vol}^{1}$ and $\mathrm{Vol}^{2}$ strains selectively eliminate expression of the VOL-1 and VOL-s integrin isoforms, respectively (Grotewiel et al., 1998).

Imprecise excision of the $\mathrm{Vol}^{1}$ insertion element generated two additional alleles, $\mathrm{Vol}^{3}$ and $\mathrm{Vol}^{4}$, which are homozygous-lethal in larval stages. PCR and sequence analysis of the Volado gene in these two excision mutants reveals that both delete portions of the open reading frame common to both transcripts (exons 2-8). The $\mathrm{Vol}^{3}$ allele deletes $925 \mathrm{bp}$ of the locus, including all of exon 3 and parts of exons 2 and 4; the deleted region includes the three consensus divalent cation-binding domains essential for integrin function. The $\mathrm{Vol}^{4}$ allele deletes $1640 \mathrm{bp}$, including the first $118 \mathrm{bp}$ of exon 2 and $1522 \mathrm{bp}$ of the preceding intron. Molecular criteria predict these two mutations to be null alleles.

All fly stocks were maintained at $25^{\circ} \mathrm{C}$ on standard cornmeal medium supplemented with dry yeast. Balanced stocks carrying the $\mathrm{Vol}^{3}$ or $\mathrm{Vol}^{4}$ chromosomes were crossed to $y w ; S c o / C y O y^{+}$flies to generate new balanced Volado mutant strains $\left(y w ; \mathrm{Vol}^{-} / \mathrm{CyO}^{+}{ }^{+}\right.$). Wild-type (Oregon R), $y w$ and ry control, and Volado mutant flies were transferred daily to fresh tubes for a laying period of $<24 \mathrm{hr}$. Wild-type (Oregon-R) and lethal $V o l$ mutant animals used for developmental studies of VOL protein expression and synaptic morphology analyses were selected from midembryonic stages [10 hr after egg laying (AEL)], to mature (wandering) third instar stages ( $\sim 6 \mathrm{~d}$ after hatching). Mature third instar larvae were used for all other experiments. Homozygous $\mathrm{Vol}^{3}$ and $\mathrm{Vol}^{4}$ larvae were selected at $\sim 3 \mathrm{~d}$ AEL by the $y^{-}$marker and transferred to new tubes for the remainder of development. At late third instar stages, the surviving $\mathrm{Vol}$ mutant larvae $(10-20 \%)$ rarely exhibit normal wandering behavior, and most are undersized and weak compared to control and viable mutant larvae. We selected the most robust and normal-appearing $\mathrm{Vol}$ survivors to avoid including data from animals near lethality; selected animals (6-7 d AEL) were comparable or slightly smaller in size compared to control larvae.

For conditional rescue experiments, we used the Volado transgene (VS-T3) containing the Volado-short genomic sequence driven by the heat-shock promoter hsp70 (Grotewiel et al., 1998). This T3 transgene was crossed onto the $\mathrm{Vol}^{3}$ and $\mathrm{Vol}^{4}$ mutant second chromosomes by standard crosses and confirmed by PCR (our unpublished results), and the resulting $\mathrm{Vol}^{3}-\mathrm{T} 3$ and $\mathrm{Vol}^{4}-\mathrm{T} 3$ constructs were balanced over CyO GFP. Homozygous $\mathrm{Vol}^{3}-\mathrm{T} 3$ and $\mathrm{Vol}^{4}-\mathrm{T} 3$ larvae were selected at $3 \mathrm{~d}$ AEL and transferred to agar plates supplemented with wet yeast or food tubes. Animals were heat-shocked by immersing sealed tubes or plates in a water bath $(30 \mathrm{~min}$ at $37^{\circ} \mathrm{C}$ ) once per day on days 3-6 AEL, or alternatively, three times over a $36 \mathrm{hr}$ period on days 6-7 AEL. $\mathrm{Vol}^{3}-\mathrm{T} 3$ and $\mathrm{Vol}^{4}-\mathrm{T} 3$ larvae receiving $\mathrm{HS}$ display markedly improved growth, robust movement, and improved viability compared to homozygous $\mathrm{Vol}^{3}$ and $\mathrm{Vol}^{4}$ larvae; the majority of heat-shocked $\mathrm{Vol}^{3}-\mathrm{T} 3$ and $\mathrm{Vol}^{4}-\mathrm{T} 3$ animals survive to midpupal stages, and a minority are rescued to adult viability. All physiological recordings were made from heat-shocked $\mathrm{Vol}^{4}$-T3 larvae. Again, we observed no significant differences in average transmission amplitude or short-term facilitation properties between larvae receiving either HS treatment, and these results are pooled in Figure 7, $A$ and $B$; all results in Figure $7 C$ were obtained from animals given four HS treatments over days 3-6 AEL.

Synaptogmin-GFP and Synaptobrevin-GFP flies were constructed and kindly supplied by Dr. Yong Zhang. Enhanced GFP (catalog \#6084-1; Clontech, Palo Alto, CA) was fused to the C-terminal of synaptotagmin (GenBank accession number M55048) and n-synaptobrevin (GenBank accession number S66686). The fusion constructs were then introduced into Drosophila transformation vector $\mathrm{pP}\{\mathrm{UAST}\}$ (FlyBase, 2000) under the control of UAS. Transformants were crossed to elav-GFP or 4G-GFP flies to drive expression pan-neuronally or in a subset of central neurons, respectively. Neurally expressed neuronal Synaptobrevin-GFP (n-Syb GFP) has recently been reported to be normally transported and specifically localized to synaptic vesicle membranes at Drosophila NMJs (Estes et al., 2000).

Immunohistology. Preparations were fixed and immunohistologically stained as reported previously (Broadie and Bate, 1993; Broadie et al., 1995; Rohrbough et al., 1999). The rabbit polyclonal Volado antibody was raised against the protein $C$ terminus and recognizes both adult VOL isoforms (Grotewiel et al., 1998). Larvae were dissected along the dorsal midline and secured flat with pins or histoacryl glue in $\mathrm{Ca}^{2+}$-free saline, fixed for $45-75 \mathrm{~min}$ with $4 \%$ paraformaldehyde in PBS, then washed in PBS-TX $(0.1 \%$ Triton X-100 in PBS) containing $5 \mathrm{mg} / \mathrm{ml} \mathrm{BSA.} \mathrm{Prepara-}$ tions were then stained overnight at $4^{\circ} \mathrm{C}$ with rabbit polyclonal anti-Volado (1:50), rat monoclonal anti-Disks-large (DLG; 1:500), or mouse monoclonal anti-cysteine string protein (CSP; 1:100) antibodies, followed by incubation with a biotinylated (Volado, CSP) secondary antibody (1:300 to 1:500) for $2 \mathrm{hr}$ at room temperature. All antibody dilutions were in PBS-TX. Volado and CSP immunostaining was visualized using a Vectastain ABC Elite kit (Vector Laboratories, Burlingame, CA) with DAB reaction and $\mathrm{NiCl}_{2}$ enhancement, as reported previously (Broadie and Bate, 1993; Broadie et al., 1995; Rohrbough et al., 1999). Preparations were dehydrated with an ethanol series, cleared in Histoclear, mounted in araldite, and visualized with Nomarski optics at $1000 \times$ on a Zeiss Axioskop microscope. In fluorescent antibody-labeling experiments for confocal analysis, immunostaining was visualized with fluorescence-conjugated streptavidin (1:500) bound to biotinylated secondary antibody (Volado), or with directly conjugated fluorescent secondary antibodies (DLG, CSP). As controls for the specificity of the Volado antibody, we stained embryos homozygous for a Volado deficiency; additionally, we treated wild-type larvae with rabbit preimmune serum or with anti-rabbit secondary antibody only. No specific staining was observed in these cases.

Optical sections of the CNS and NMJs were collected for analysis on a Bio-Rad (Hercules, CA) MRC 600 confocal microscope. Color images and microscopy figures were constructed and manipulated using Adobe Photoshop software.

NMJ morphological analysis. Anti-CSP-stained NMJs in wild-type, $y w$ control, and lethal $\mathrm{Vol}$ mutant $\left(\mathrm{Vol}^{3}\right.$ and $\left.\mathrm{Vol}^{4}\right)$ larvae were viewed at $1000 \times$ on a Zeiss Axioskop microscope. The number of type I terminal branch segments (muscle 4) and synaptic boutons (muscles 4 and 6/7) were counted in both hemisegments of abdominal segment A3 and averaged for each larva. Branches originating directly from the nerve entry point were classified as primary branches, and each subsequent branch fork with at least two boutons defined progressively higher-order (i.e., secondary, tertiary) segments (Rohrbough et al., 1999). Average bouton and branch numbers were determined from 12 control larvae and 8 larvae from each mutant strain. Only the principle NMJ formed near the internal center of the muscle and containing type Ib boutons, was analyzed. We observed no significant morphological differences between wild-type OR and $y w$ control animals. Digital images of representative terminals were collected at $400 \times$ using a SPOT digital camera and image acquisition software (Zeiss).

Electrophysiology. All recordings were made at $18^{\circ} \mathrm{C}$ from muscle 6 in abdominal segments A3-A4 of freshly dissected third instar larvae, as described previously (Rohrbough et al., 1999). Two electrode voltageclamp recordings were made at a holding potential of $-60 \mathrm{mV}$ with an Axoclamp 2B amplifier (Axon Instruments, Burlingame, CA). Dissections and recordings were made in modified standard Drosophila saline (Jan and Jan, 1976) containing additional sucrose, composed of (in $\mathrm{mM}$ ): $128 \mathrm{NaCl}$, $2 \mathrm{KCl}, 4 \mathrm{MgCl}_{2}, 5$ trehalose, 70 sucrose, 5 HEPES, and $0.15-1.5 \mathrm{CaCl}_{2}$; pH-adjusted to 7.1 with NaOH. Gly-Arg-Gly-Asp-Ser-Pro (GRGDSP) inhibitory and Gly-Arg-Ala-Asp-Ser-Pro (GRADSP) control peptides (Calbiochem-Novabiochem, San Diego, CA) were initially solubilized at 2 $\mathrm{mM}$ in $0.2 \mathrm{mM} \mathrm{Ca}^{2+}$ saline containing $0.02 \%$ acetic acid and frozen in $\sim 1$ $\mathrm{ml}$ aliquots. Aliquots were diluted to a final peptide concentration of 0.2 $\mathrm{mM}$ in $0.2 \mathrm{mM} \mathrm{Ca}^{2+}$ saline $(\mathrm{pH} 7.1 \pm 0.1)$ on the day of use. Intracellular electrodes were filled with a 3:1 mixture of $3 \mathrm{M} \mathrm{K}^{+}$acetate: $\mathrm{KCl}$ and had resistances of $8-15 \mathrm{M} \Omega$. Segmental nerves were severed near the CNS to eliminate junctional responses originating from CNS activity, and excitatory junctional currents (EJCs) were evoked by stimulating $(0.4-1 \mathrm{msec})$ the severed nerve at $0.2-20 \mathrm{~Hz}$ frequencies with a suction electrode filled with external saline. Miniature excitatory junctional currents (mEJCs) were recorded at $-60 \mathrm{mV}$ in $0.2 \mathrm{mM} \mathrm{Ca}^{2+}$ saline containing $0.1 \mu \mathrm{g} / \mathrm{ml}$ TTX. Currents were filtered $(500-1000 \mathrm{~Hz})$, digitized to disk $(5 \mathrm{kHz})$, and analyzed using pClamp6 acquisition and analysis hardware and software (Axon Instruments). For continuous recordings of mEJCs, and EJCs in post-tetanic potentiation (PTP) experiments, synaptic currents were detected, and amplitudes were measured as described previously (Rohrbough et al., 1999), using event-detection and analysis software (ACSPLOUF) written and provided by Dr. P. Vincent. Exemplar EJC traces were averaged from 5-10 consecutive individual responses, except for the individual events shown in Figures $4 B$ and $5 A$. Event averaging and amplitude analysis was performed using pClamp6 and commercial spreadsheet software.

Statistical analysis was performed using Instat Graphpad software. All data are presented as mean \pm SEM unless otherwise indicated.

\section{RESULTS}

\section{Volado protein expression at central and peripheral synaptic connections}

A role for Volado in memory mechanisms predicts that the VOL protein is expressed at synaptic connections. To investigate neuronal and synaptic VOL expression during development, we stained wild-type embryonic and larval preparations with a polyclonal antibody that recognizes both VOL isoforms (Grotewiel et al., 1998; see Materials and Methods). VOL immunostaining is not detected in the nervous system before early second instar $(\sim 24 \mathrm{hr}$ after hatching; data not shown), but thereafter VOL protein is detectable both in the CNS and at the NMJ. In the CNS, conventional and confocal microscopy reveals VOL to be consistently and distinctly localized to numerous $0.2-$ to $2-\mu \mathrm{m}$-diameter puncta in the ventral nerve cord neuropil (Fig. $1 A$ ). These puncta, which appear to be synaptic boutons, are distributed primarily throughout 
Figure 1. Volado (VOL) protein is localized to synaptic connections in the central neuropil. $A$, VOL expression in the CNS neuropil of third instar wild-type larvae. Left, VOL is localized to $0.2-$ to $2-\mu \mathrm{m}$ diameter puncta resembling synaptic boutons (arrows) within the central neuropil (np, neuropil; $v m$, ventral midline). Center left and right, Confocal images of localized VOL expression (in green) at synaptic boutons in the central neuropil; magnification is increased twofold in center right panel. Images are Z-series projections of five $1 \mu \mathrm{m}$ sections (left) and eight $1 \mu \mathrm{m}$ sections (right). VOL synaptic bouton staining is absent in the central neuropil of a third instar $\mathrm{Vol}^{4}$ mutant larva (Z-series projection of six $1 \mu \mathrm{m}$ sections (rightmost panel). Scale bar: Left, center left, $20 \mu \mathrm{m}$; center right, right, 10 $\mu \mathrm{m}$. B, Comparison of VOL CNS expression with presynaptic Syt and Syb proteins. Left, Z-series (8 $\mu \mathrm{m}$ depth) image of panneuronally driven Syt [gal4 (elav): Syt-GFP] concentrated throughout the entire central neuropil; line indicates neuropil margins. Compare with left panels in A. The bottom panel shows a higher magnification image in the neuropil of another CNS; Syt-GFP synaptic puncta (arrows) are visible within a background of Syt expression. Center left, Syb-GFP (green) expressed in a subset of central neurons [gal4 (4G): Syb-GFP] to better visualize synaptic puncta and aggre-

gates. VOL punctate expression (red) is completely contained within the Syb-GFP expression domain in the synaptic neuropil. VOL occasionally also labels a few laterally situated cell bodies. Image is a Z-series of $11 \mu \mathrm{m}$ depth. Center right, A second Z-series image $(4 \mu \mathrm{m}$ depth) from the boxed region at higher magnification; arrows indicate examples of discrete synaptic puncta labeled by both markers. Right panels, Magnified examples of VOL, Syb-GFP, and Syt-GFP synaptic puncta, showing similarity of the localized synaptic expression of all three proteins. Syb- and Syt-GFP are expressed in a subset of neurons using the gal4 $(4 \mathrm{G})$ driver. Scale bars: top left, center left, $20 \mu \mathrm{m}$; all other panels, $10 \mu \mathrm{m}$.

\section{A anti-VOL}

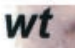

np
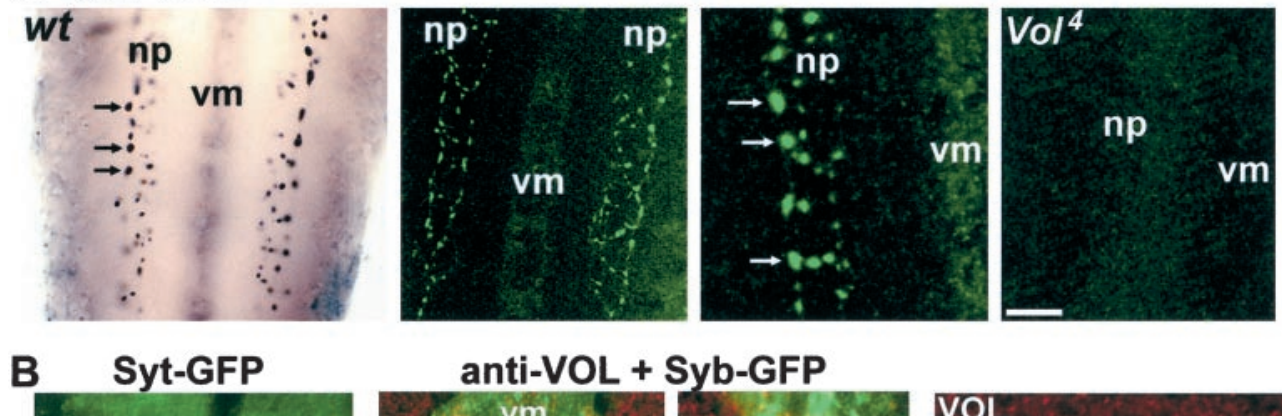

anti-VOL + Syb-GFP
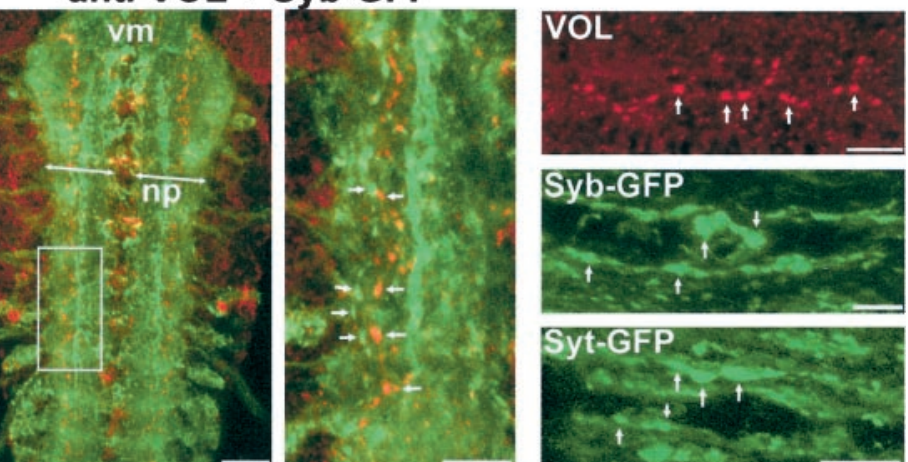

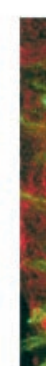

a path of 10-20 $\mu \mathrm{m}$ width running the length of the ventral nerve cord (VNC), although the number and specific pattern of distinguishable VOL-positive boutons is variable among individual preparations. In addition, VOL appears to be less distinctly concentrated in the VNC midline (Fig. $1 A$, center panels, $B$, center left) and occasionally in a few laterally situated neuronal soma (Fig. $1 B)$. We compared VOL expression pattern in the VNC with that of synaptic vesicle GFP-fusion proteins, Synaptotagmin- (Syt) and Synaptobrevin- (Syb) GFP, transgenically expressed pan-neuronally [using a gal4 (elav) driver] or in a neuronal subset [using a gal4 (4G) driver] (Fig. 1B). In double-labeled CNS preparations, VOL puncta are always contained within the highly concentrated and broader area of Syt- or Syb-GFP expression in the neuropil (Fig. $1 B$, left and middle), indicating that VOL expression is limited to a small subset of the central neurons and boutons labeled by these two proteins. When expressed in a neuronal subset, both Syt- and Syb-GFP are also observed in densely concentrated puncta and larger aggregate patches, which presumably are individual synapses or synaptic clusters (Fig. $1 B$, right). These synaptic structures are present in the same neuropil regions as VOL and strongly resemble VOL puncta in their size and distribution, further suggesting that VOL is localized to subsets of synaptic boutons. VOL immunoreactivity is completely absent or only weakly detected in the CNS of third instar $\mathrm{Vol}^{3}$ and $\mathrm{Vol}^{4}$ mutants (see below) (Fig. 1A, right). Strong VOL immunostaining is also present in the salivary glands, midgut, and dorsal vessel of wild-type embryos; this staining is absent in embryos homozygous for a Volado deficiency (data not shown). Both of these controls indicate specificity of the antibody for the VOL protein.

The VOL protein is also localized to the NMJ throughout late larval development (Fig. 2). At the majority of NMJs in wild-type larvae, VOL immunostaining in the synaptic terminal is present only at low levels near the limit of detection (Fig. 2A). This expression is distinctive compared to that of the other known Drosophila synaptic integrins ( $\alpha \mathrm{PS} 1, \alpha \mathrm{PS} 2, \beta \mathrm{PS})$, which are strongly concentrated at all large (type Ib and Is) synaptic boutons at the NMJ (Beumer et al., 1999). However, strong bouton-specific VOL expression is clearly present in a subset of synaptic boutons at
NMJs in nearly all third instar larvae (44 of 47 examined; Table 1). Localized VOL expression is found in as few as 1-3 boutons, to as many as one or two dozen, of the several dozens to hundreds of synaptic boutons composing the synaptic terminal. VOL is clearly localized to both large type I boutons as well as smaller type II and III boutons at multiple classes of NMJs (Fig. 2B,C, Table 1). The highest frequency of strong synaptic bouton expression $(23 \%)$ occurs at the muscle 12/13 NMJ, a complex terminal that receives all three types of innervation (Fig. 2C); however, comparable localized expression was observed at all other classes of NMJs examined (Table 1). At NMJs double-stained against VOL and the presynaptically localized cysteine string protein (CSP), VOL and CSP appear to be colocalized at multiple types of boutons (Fig. $1 C$ ), suggesting that VOL has a primarily presynaptic localization. Thus, as in the CNS, localized VOL expression at the NMJ appears to be restricted to a small and variable subset of synaptic boutons in individual animals at a given time.

These synaptic protein expression characteristics are unique to VOL among the other PS integrins and other known Drosophila synaptic proteins described to date. However, VOL is clearly a highly, if variably, expressed synaptic protein, and a functional role for VOL at synaptic connections is supported by the strong, broadranging synaptic phenotypes observed in Volado mutants, described below.

\section{Morphological synaptic overgrowth at Volado mutant NMJs}

The Volado gene encodes two mRNA transcripts (Stark et al., 1997; Grotewiel et al., 1998), previously designated Vol-long (Vol-1) and Vol-short (Vol-s) (Grotewiel et al., 1998). Both transcripts are expressed throughout the majority of embryonic and larval development, as well as in adults (Stark et al., 1997; Grotewiel et al., 1998). The viable $\mathrm{Vol}^{1}$ and $\mathrm{Vol}^{2}$ mutant alleles selectively eliminate Vol-1 and $\mathrm{Vol}$-s expression, respectively (Grotewiel et al., 1998). The $\mathrm{Vol}^{3}$ and $\mathrm{Vol}^{4}$ alleles were generated by imprecise precision of the P-element inserted into the Volado gene and contain deletions in the Volado coding region predicted to eliminate both VOL protein isoforms (see Materials and Methods). These alleles are 

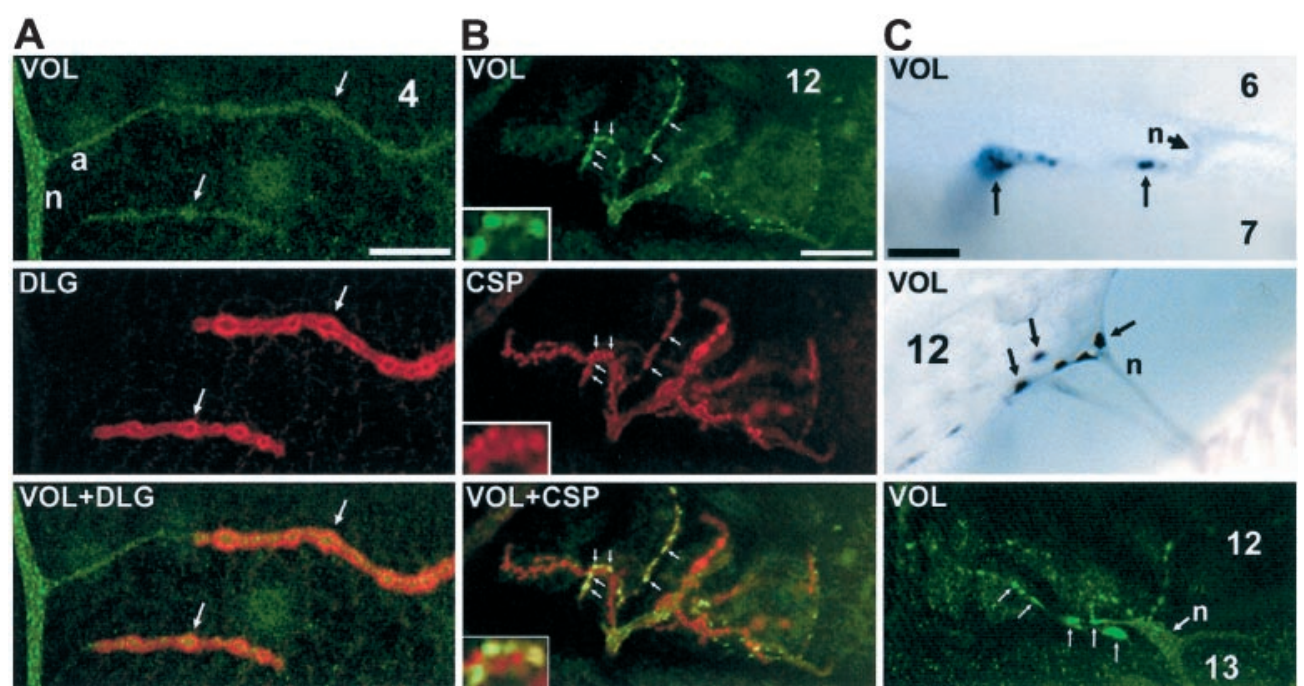

Figure 2. VOL is localized to synaptic boutons at the NMJ in wild-type third instar larvae. $A$, Confocal images at a type I NMJ (muscle 4) double-stained with antibodies against VOL (top, green) and the primarily postsynaptic Disks-large $(D L G)$ protein (center, red), which is localized to all type I boutons. VOL immunostaining is weakly observed in nerve branches $(n)$, presynaptic axons $(a)$, and the synaptic terminal arbor. Arrows indicate two individual type I boutons. Bottom panel shows the green and red images merged. Scale bar, $10 \mu \mathrm{m}$. $B$, Confocal images at a muscle 12 NMJ, which receives multiple (type I, II, and III) innervation, double-stained against VOL (top, green) and the presynaptic CSP protein (center, red). VOL immunostaining is strongly localized to multiple subtypes of synaptic boutons ( $a r-$ rows); insets show several VOL-positive boutons at threefold greater magnification. VOL staining colocalizes with CSP staining, suggesting VOL localization is primarily presynaptic. Bottom panel shows the green and red images merged. Scale bar, $10 \mu \mathrm{m}$. C, Conventional (top and center) and confocal images (bottom) of variable VOL immunostaining at NMJs. Strong VOL localization is observed in a small subset of boutons at each terminal. Scale bars, $10 \mu \mathrm{m}$ in each panel.

Table 1. Summary of Volado immunoreactivity in Drosophila larvae

\begin{tabular}{|c|c|c|c|c|c|c|c|}
\hline Stage & $\begin{array}{l}\text { Number } \\
\text { of larvae }\end{array}$ & $\begin{array}{l}\% \text { VOL }(+) \text { in } \\
\text { CNS neurophil }\end{array}$ & $\begin{array}{l}\% \operatorname{Vol}(+) \\
\text { at } \mathrm{NMJ}\end{array}$ & $\begin{array}{l}\text { Number of } \\
\text { hemisegments scored }\end{array}$ & $\%$ NMJs VOL $(+)$ & $\mathrm{NMJ}$ & $\% \operatorname{VOL}(+)$ \\
\hline \multirow[t]{2}{*}{$2^{\text {nd }}$ instar $(24-30 \mathrm{hr}$ AH) } & 12 & 67 & 42 & 81 & 2.3 & $6 / 7$ & 3.7 \\
\hline & & & & & & $12 / 13$ & 14.8 \\
\hline \multirow[t]{3}{*}{$3^{\text {rd }}$ instar $(\sim 96 \mathrm{hr} \mathrm{AH})$} & 47 & 100 & 94 & 420 & 5.1 & 4 & 2.9 \\
\hline & & & & & & $6 / 7$ & 4.5 \\
\hline & & & & & & $12 / 13$ & 22.6 \\
\hline
\end{tabular}

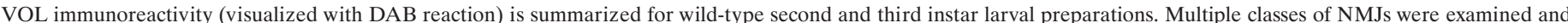

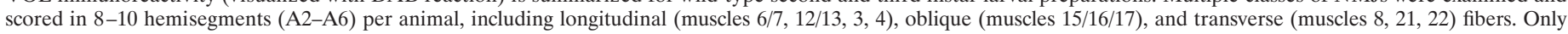

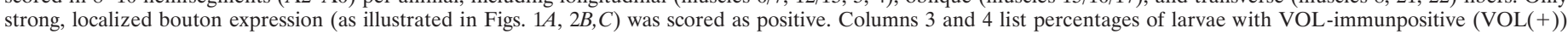

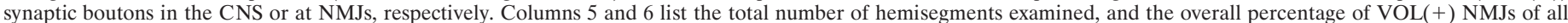

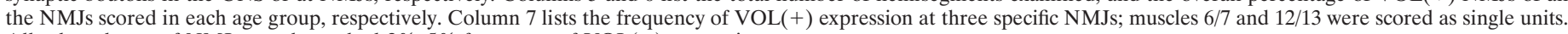
All other classes of NMJs not shown had 2\%-5\% frequency of VOL $(+)$ expression.

thus considered to be either strong hypomorphs or nulls. Homozygous $\mathrm{Vol}^{3}$ and $\mathrm{Vol}^{4}$ mutant embryos hatch normally but exhibit increasingly impaired locomotion in larval stages. Most mutant larvae die during second and third instars. Although 10-20\% survive to mature third instar stage (5-6 d after hatching), few pupate and none survive through metamorphosis to adult stages.

$\mathrm{Vol}^{3}$ and $\mathrm{Vol}^{4}$ mutant embryos show no obvious defects in neuronal pathfinding or synaptogenesis at the NMJ. Likewise, CNS morphology, peripheral nerve branching, neuromuscular patterning, and number and distribution of NMJs all appear normal in the mutant larvae at hatching (data not shown). However, beginning in the mid-second instar ( $\sim 30 \mathrm{hr}$ after hatching), $\mathrm{Nol}^{3}$ and $\mathrm{Vol}^{4}$ NMJs exhibit morphological overgrowth in several respects compared to normal. At two NMJs (6/7 and 4) analyzed in third instar larvae, mutant terminals are significantly enlarged and overgrown, exhibiting 60-100\% more synaptic terminal branches and $30-40 \%$ more synaptic boutons than NMJs in control larvae (Fig. 3 ). These results suggest that VOL has a role in limiting morphological synaptic terminal growth at most, if not all NMJs despite its limited localization in most terminals at a given time.

\section{Altered amplitude and $\mathrm{Ca}^{2+}$ dependence of transmission at Volado mutant synapses}

Functional synaptic transmission properties were recorded at the $\mathrm{NMJ}$ in third instar larvae both for the viable $\mathrm{Vol}^{1}$ and $\mathrm{Vol}^{2}$ hypomorphs that display adult STM defects and for the lethal $\mathrm{Vol}^{3}$ and $\mathrm{Vol}^{4}$ alleles. At a physiological level of external $\mathrm{Ca}^{2+}(1.5 \mathrm{~mm})$, mutant NMJs display essentially normal transmission. EJCs evoked at basal stimulation frequencies $(0.2-0.5 \mathrm{~Hz})$ have comparable peak amplitudes and variability in both viable and lethal $\mathrm{Vol}$ mutants as in $y w$ control larvae $(241 \pm 19 \mathrm{nA}, y w ; 278 \pm 18 \mathrm{nA}$, $\mathrm{Vol}^{1} ; 225 \pm 32 \mathrm{nA}, \mathrm{Vol}^{2} ; 265 \pm 13 \mathrm{nA}, \mathrm{Vol}^{3} ; 212 \pm 17 \mathrm{nA}, V_{o l}^{4}$; $n \geq 6$ for each genotype) (Fig. $4 A, C$ ), as well as normal responses to higher frequency stimulation $(10-20 \mathrm{~Hz}$; data not shown). However, as external $\mathrm{Ca}^{2+}$ concentration is progressively reduced $(<0.5 \mathrm{~mm})$, EJC amplitudes display greater variability among mutant larvae and larger overall mean amplitudes (Fig. $4 A-C$ ). In 0.2 $\mathrm{mM} \mathrm{Ca}{ }^{2+}$, the elevated transmission is least pronounced for $\mathrm{Vol}^{2}$ animals, but highly significant for the $\mathrm{Vol}^{1}, \mathrm{Vol}^{3}$, and $\mathrm{Vol}^{4}$ alleles $(p<0.01$, ANOVA and Dunn's multiple comparisons test), which each have threefold to fourfold larger EJC amplitudes on average than control larvae (Fig. 4B). The indistinguishable transmission phenotypes for these latter three alleles indicate that the altered synaptic function is attributable to a deficiency in VOL and not to the lethality associated with $\mathrm{Vol}^{3}$ and $\mathrm{Vol}^{4}$ mutants. Over the 0.15-0.25 mM concentration range, Ool $^{2}$ transmission displays normal dependence on external $\mathrm{Ca}^{2+}$, exhibiting a slope of 3.6 for the logarithmic relationship between EJC amplitude and $\mathrm{Ca}^{2+}$ concentration, compared to a control slope of 3.7. By contrast, the other three $\mathrm{Vol}$ mutant alleles each display reduced slopes, ranging from 2.6 to 2.9 , indicating similarly reduced $\mathrm{Ca}^{2+}$ dependence of transmission (Fig. 4C).

To determine whether increased mutant EJC amplitudes result from greater number of postsynaptic glutamate receptors or from increased probability of quantal transmitter release, we recorded spontaneous mEJCs in control, $\mathrm{Vol}^{3}$, and $\mathrm{Vol}^{4}$ larvae in $0.2 \mathrm{~mm}$ $\mathrm{Ca}^{2+}$. Control and mutant NMJs have indistinguishable mEJC variability and mean amplitudes, indicating mutant postsynaptic glutamate receptor density is not significantly altered (Fig. 4D). A 
A

Figure 3. NMJs of lethal Volado mutants exhibit morphological overgrowth. $A$, Synaptic terminal morphology visualized with CSP immunostaining in $y w$ control (left panels) and $\mathrm{Vol}^{4}$ mutant third instar larvae (right panels) at the NMJs of muscle 6/7 (top) and muscle 4 (bottom). Arrows indicate individual type I synaptic boutons; the nerve branch $(n)$ and presynaptic axon $(a)$ at muscle 4 are indicated in bottom panels. $\mathrm{Vol}^{3}$ and $\mathrm{Vol}^{4}$ mutant NMJs have larger terminal arbors, increased terminal branching, and increased numbers of synaptic boutons compared to control NMJs. Scale bar, $20 \mu \mathrm{m}$. B, Quantification of terminal branching and synaptic bouton number in lethal Volado mutants. The $\mathrm{Vol}^{4}$ allele has significantly greater numbers of higher-order $\left(2-3^{\circ}\right)$ terminal branches at the muscle $4 \mathrm{NMJ}$; both $\mathrm{Vol}^{3}$ and $\mathrm{Vol}^{4}$ NMJs have significantly greater total number of branches than control NMJs (left). Synaptic bouton number is increased in both mutant alleles at both muscle 4 and muscle 6/7 NMJs (right); dots indicate significance at $\bullet<0.05$ and $\bullet \bullet p<0.01$; ANOVA and Dunnett's multiple comparisons test. Legend indicates number of larvae analyzed in both plots.
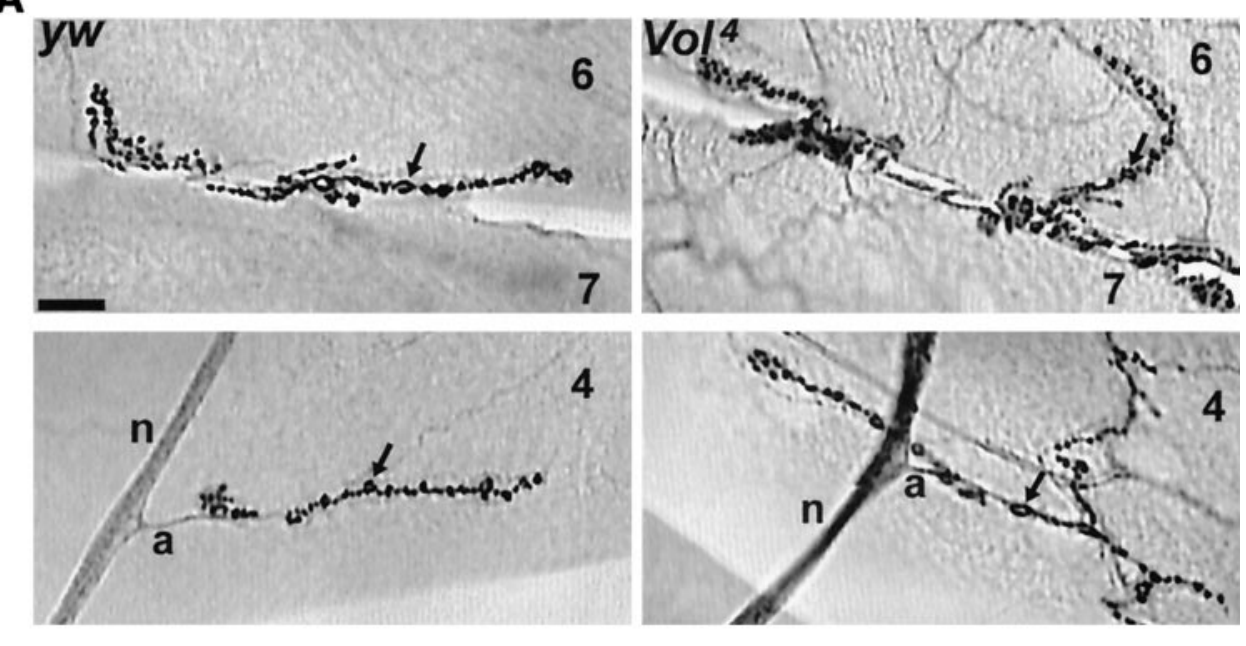

$\mathbf{B}$
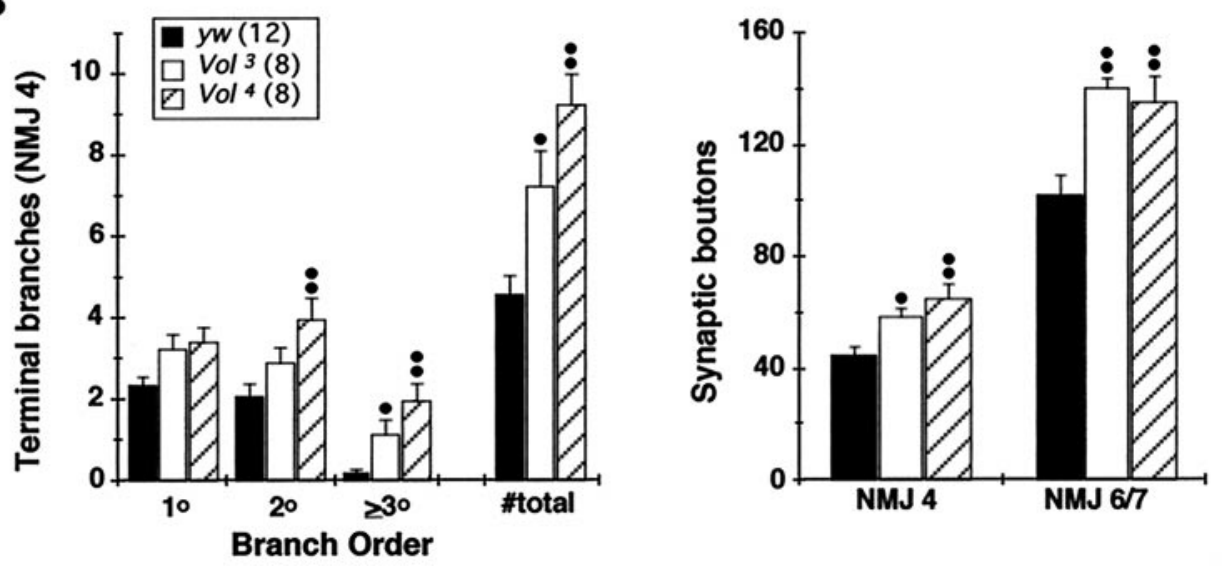

modest but significant increase in $\mathrm{mEJC}$ frequency is observed in $\mathrm{Vol}^{4}$ mutants (63\% over control; $p<0.05$ vs control; ANOVA and multiple comparisons test; Fig. 4D). This increase could be attributed to the increased number of synaptic boutons at mutant NMJs; however, mEJC frequency is not altered in $\mathrm{Vol}^{3}$ mutants, although they display the same increase in bouton number. Despite this slight allelic difference, mutant NMJs exhibit no changes in $\mathrm{mEJC}$ amplitude or frequency sufficient to account for the threefold to fourfold increase in evoked EJC amplitude under the same recording condition. We therefore conclude that VOL specifically regulates $\mathrm{Ca}^{2+}$-dependent, evoked neurotransmitter release processes.

\section{Loss of functional plasticity at Volado mutant synapses}

To assess the role of VOL in synaptic modulation processes, we next examined several forms of $\mathrm{Ca}^{2+}$ - and activity-dependent plasticity previously shown to be altered in other Drosophila learning/memory mutants (Zhong and Wu, 1991; Wang et al., 1994; Broadie et al., 1997; Rohrbough et al., 1999). Volado mutant NMJs display significant defects in two forms of short-term facilitation, paired-pulse facilitation (PPF) and frequency-dependent shortterm facilitation (STF), measured in $0.2 \mathrm{mM} \mathrm{Ca}^{2+}$ (Fig. 5). At control NMJs, EJC amplitude is facilitated (PPF) by paired stimuli at $20-100 \mathrm{msec}$ intervals, with approximately twofold PPF at 20 msec intervals (Fig. 5A). For the $\mathrm{Vol}^{2}$ allele, which has basal transmission properties most similar to control, PPF is essentially normal. Among the other three mutant strains, which all exhibit strongly elevated, or "prefacilitated" EJC amplitudes in $0.2 \mathrm{~mm}$ $\mathrm{Ca}^{2+}, \mathrm{PPF}$ in $\mathrm{Vol}^{1}$ animals is reduced by $\sim 35 \%$ at the briefest interval (20 msec), and more severely reduced (by 50-60\%) for the $\mathrm{Vol}^{3}$ and $\mathrm{Vol}^{4}$ alleles at 20-30 msec intervals (Fig. 5A). Pairedpulse depression, which was never observed in controls, also occurred in several $\mathrm{Vol}^{3}$ and $\mathrm{Vol}^{4}$ animals (data not shown).
Control EJC amplitudes undergo rapid and reversible frequencydependent STF by as much as threefold to fourfold over initial basal amplitude, in response to short stimulus trains at $2-20 \mathrm{~Hz}$ (Fig. $5 B$ ). Mutant STF is nearly normal in $V_{o l}^{2}$ larvae, but is significantly $(40-50 \%)$ reduced at all stimulation frequencies in $\mathrm{Vol}^{1}$ larvae. The lethal $\mathrm{Vol}$ alleles exhibit severely $(>65 \%)$ reduced STF relative to control levels. STF defects are particularly severe in many $\mathrm{Vol}^{4}$ larvae. In 9 of $17 \mathrm{Vol}^{4}$ animals, facilitation was either absent, or strikingly, gave way to depression during $10-20 \mathrm{~Hz}$ stimulus trains (Fig. 5B, bottom traces). Basal transmission amplitudes, PPF, and STF were also indistinguishable from $y w$ animals in $r y$ control larvae (Figs. $3 B, 4$ ), ruling out any functional abnormality associated with the ry chromosome present in $\mathrm{Vol}^{1}$ and $\mathrm{Vol}^{2}$ mutants (Grotewiel et al., 1998; see Materials and Methods). These results indicate that VOL is required for normal short-term, $\mathrm{Ca}^{2+}$. dependent synaptic facilitation processes.

During more prolonged stimulation at intermediate frequencies (5-10 Hz), the Drosophila NMJ displays sustained augmentation of transmission amplitude and PTP after tetanic stimuli. Control NMJs display greater than twofold augmentation after $60 \mathrm{sec}$ stimulation at $5 \mathrm{~Hz}$ and sustained PTP of $60-65 \%$ over initial EJC amplitude for $>5 \mathrm{~min}\left(0.2 \mathrm{mM} \mathrm{Ca}^{2+}\right.$; Fig. 6$)$. The Volado mutant alleles display impaired augmentation and PTP paralleling the severity of STF defects described above. The $\mathrm{Vol}^{1}$ allele, which has an intermediate severity of impaired STF, displays reduced augmentation to $\sim 75 \%$ over initial amplitudes and PTP reduced to $70-75 \%$ of control strength (Fig. 6B). The $\mathrm{Vol}^{2}$ allele, which has essentially normal STF, also displays strong average augmentation that peaks near control levels. However, $\mathrm{Vol}^{2}$ transmission amplitude decreases dramatically immediately after the tetanus, exhibiting only $\sim 40 \%$ initial and $\sim 30 \%$ sustained PTP, respectively; 
A

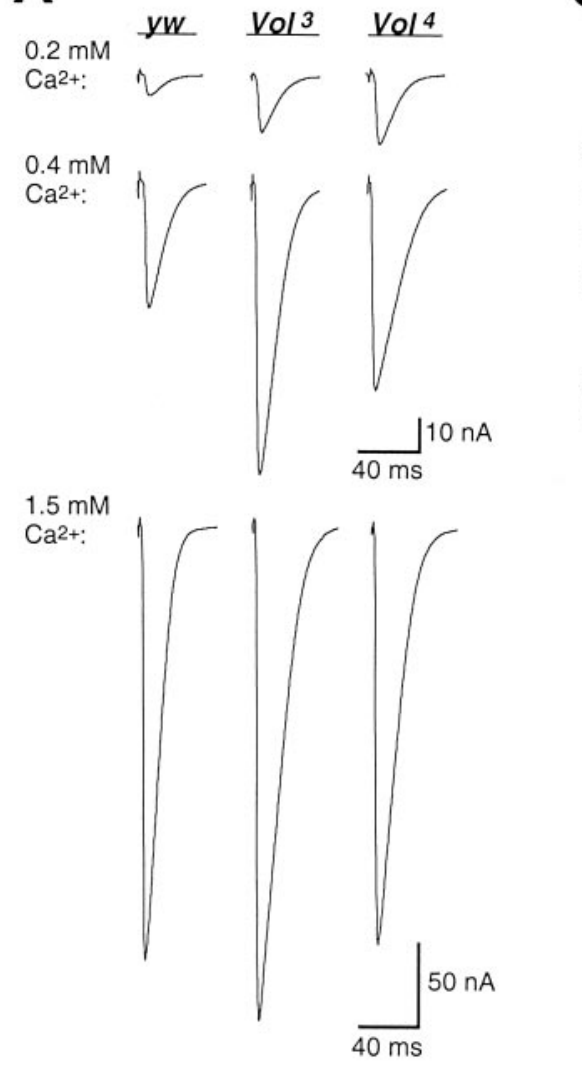

B

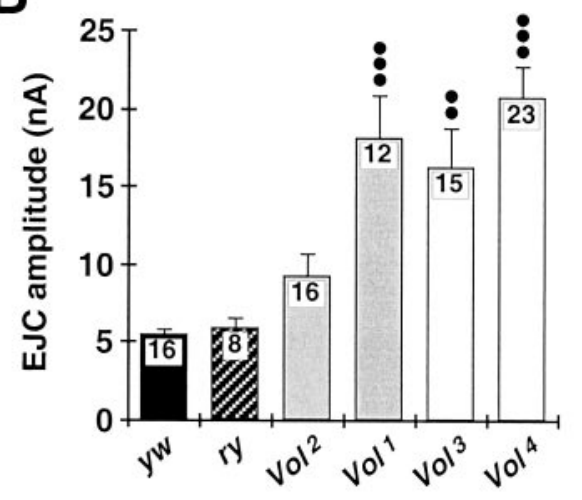

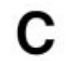

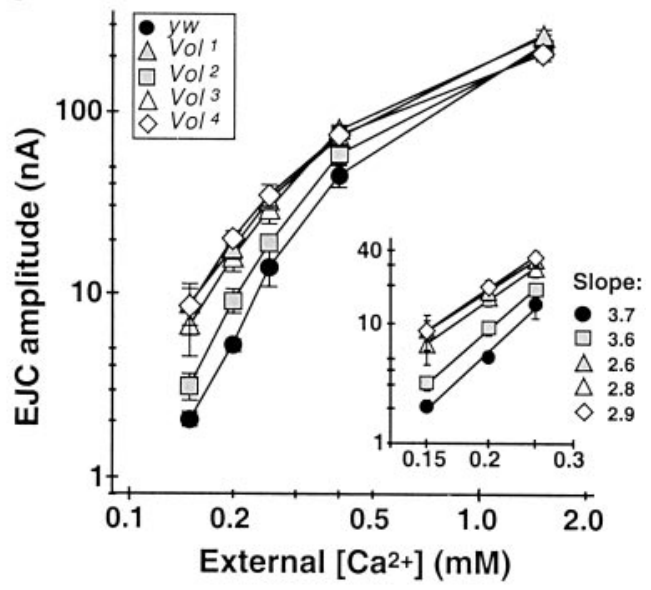

D
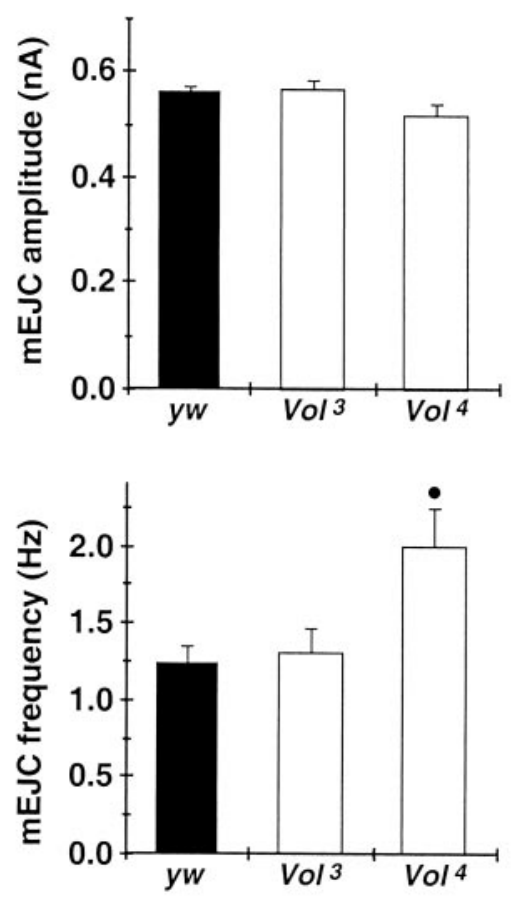

Figure 4. Increased synaptic transmission amplitude and decreased $\mathrm{Ca}^{2+}$ dependence of evoked transmitter release at $\mathrm{Vol}$ mutant NMJs. $A$, EJCs recorded from $y w$ control and lethal $V o l$ mutant $\left(\mathrm{Vol}^{3}, \mathrm{Vol}^{4}\right)$ larvae in $0.2 \mathrm{mM}$ (top), 0.4 $\mathrm{mM}$ (middle), and $1.5 \mathrm{~mm}$ external $\mathrm{Ca}^{2+}$ (bottom). Each trace shows the average of 10 consecutive EJCs evoked at basal stimulation frequency $(0.2-0.5 \mathrm{~Hz})$. Mutant EJC amplitudes deviate significantly from those in control animals in $0.4 \mathrm{~mm}$ or lower external $\mathrm{Ca}^{2+}$. All recordings were made from muscle 6 in abdominal segments A3-A4 of third instar larvae at $18^{\circ} \mathrm{C}$. $B$, Mean EJC amplitudes in $0.2 \mathrm{mM} \mathrm{Ca}^{2+}$ for $y w$ and ry control larvae (solid and hatched bars, respectively), viable $\mathrm{Vol}$ mutants $\left(\mathrm{Vol}^{1}\right.$, $\mathrm{Vol}^{2}$; shaded bars), and lethal $\mathrm{Vol}$ mutants $\left(\mathrm{Vol}^{3}\right.$ $\mathrm{Vol}^{4}$; open bars). EJC amplitudes among $\mathrm{Vol}$ mutant larvae exhibit significantly greater variability than in control larvae $(p<0.0001$; oneway ANOVA). Mean EJC amplitude for $\mathrm{Vol}^{2}$ larvae is elevated but not significantly different from control. Mean EJC amplitudes for $\mathrm{Vol}^{1}$, $\mathrm{Vol}^{3}$, and $\mathrm{Vol}^{4}$ mutants are significantly greater than for control larvae $\left(\bullet p<0.01, \mathrm{Vol}^{3}\right.$; $\bullet$ ๑ $p<0.001, \mathrm{Vol}^{1}$ and $\mathrm{Vol}^{4}$; nonparametric ANOVA and Dunn's multiple comparisons test). Number of larvae is indicated within bars for each genotype. $C$, Logarithmic plot of mean EJC amplitudes versus external $\mathrm{Ca}^{2+}$ concentration for $y w$ control (solid circles), viable $\mathrm{Vol}$ mutants (shaded symbols), and lethal Vol mutants (open symbols). Mutant EJC amplitudes are comparable to control values at physiological $\mathrm{Ca}^{2+}$ levels $(1.5 \mathrm{mM})$ but become progressively increased relative to control EJC amplitudes at more reduced $\mathrm{Ca}^{2+}$ concentrations. Each point represents the mean value for at least five larvae from each genotype. Inset shows the data plotted for $0.15-0.25 \mathrm{mM} \mathrm{Ca}^{2+}$ concentrations and fit to power relationships (straight lines). The $\mathrm{Vol}^{2}$ allele exhibits normal dependence of transmission amplitude on external $\mathrm{Ca}^{2+}$ (slope of $3.6 \mathrm{vs} 3.7$ for control). The $\mathrm{Vol}^{1}, \mathrm{Vol}^{3}$, and $\mathrm{Vol}^{4}$ alleles exhibit strongly elevated EJCs and reduced $\mathrm{Ca}^{2+}$ dependence of transmission (slopes of 2.6, $\mathrm{Vol}^{1}$; 2.8, $\mathrm{Vol}^{3}$; and 2.9, $\mathrm{Vol}^{4}$ ). D, mEJC amplitude and frequency at $y w$ control (solid bars) and $\mathrm{Vol}^{3}$ and $\mathrm{Vol}^{4}$ mutant NMJs (open bars). mEJCs were recorded at $-60 \mathrm{mV}$ in $0.2 \mathrm{mM} \mathrm{Ca}^{2+}$ containing $0.1 \mu \mathrm{g} / \mathrm{ml}$ TTX $(n=8$ larvae for each genotype). Neither mutant allele has altered mEJC variability $(0.24 \pm 0.01 \mathrm{nA}, y w ; 0.28 \pm$ $0.02 \mathrm{nA}$, Vol $^{3} ; 0.23 \pm 0.01 \mathrm{nA}, V_{o l}{ }^{4}$ ) or mean amplitude (top plot) compared to control. mEJC frequency in $\mathrm{Vol}^{4}$ larvae is increased by $63 \%$ relative to control $(\bullet<0.05)$, but no difference is observed for $\mathrm{Vol}^{3}$ larvae (bottom plot; ANOVA and Dunnett multiple comparison test). levels even more severely reduced than for $\mathrm{Vol}^{1}$ animals (Fig. 6B). The $\mathrm{Vol}^{3}$ and $\mathrm{Vol}^{4}$ alleles display severely reduced relative augmentation and PTP compared to control larvae. $\mathrm{Vol}^{3} \mathrm{NMJs}^{3}$ on average display only weak augmentation, which increases gradually to $\sim 25 \%$ over initial amplitude; initial and sustained components of PTP are reduced to 25 and $18 \%$ over initial amplitude, respectively. At $\mathrm{Vol}^{4} \mathrm{NMJ}$, tetanic stimulation typically produces an initial depression that gradually recovers to weak $(\sim 15 \%)$ augmentation, followed by strongly reduced $(\sim 15 \%$ over initial amplitudes) average levels of PTP (Fig. 6A,B).

Because Vol mutant plasticity defects are observed in conjunction with abnormally elevated basal EJC amplitudes, we repeated PTP recordings from $\mathrm{Vol}^{4}$ larvae in $0.15 \mathrm{~mm}$ external $\mathrm{Ca}^{2+}$, at which $\mathrm{Vol}^{4}$ basal EJC amplitude $(8.5 \pm 5.7 \mathrm{nA}$, mean $\pm \mathrm{SD} ; n=$ $15)$ does not differ significantly from the control amplitude in 0.2 mM Ca ${ }^{2+}$ ( $p>0.10$; Mann-Whitney $U$ test $)$. $V_{o l}^{4}$ augmentation under this condition (Fig. 6B, hatched diamonds) is dramatically and unexpectedly increased by nearly 10 -fold, surpassing by $\sim 50 \%$ $y w$ control augmentation in $0.2 \mathrm{mM} \mathrm{Ca}^{2+}$. Despite decreasing sharply from end-tetanus levels, initial $(1 \mathrm{~min}) \mathrm{Vol}^{4} \mathrm{PTP}$ is indis- tinguishable from that of control larvae in $0.2 \mathrm{mM} \mathrm{Ca}^{2+}$. However, mutant PTP declines within 2-3 min from this initial level, and at late time points $(4-5 \mathrm{~min})$ is decreased to the range observed for $\mathrm{Vol}^{2}, \mathrm{Vol}^{3}$, and $\mathrm{Vol}^{4}$ mutants in $0.2 \mathrm{mM} \mathrm{Ca}^{2+}$. Thus, sustained PTP under these conditions remains impaired at the mutant NMJ.

\section{Expression of Volado transgene in lethal Vol mutant larvae rescues transmission defects}

To provide direct evidence that VOL has a specific role in synaptic transmission and plasticity mechanisms, we attempted to rescue mutant transmission and plasticity defects by driving conditional expression of the $\mathrm{Vol}$-s transcript with a heat-shock promoter (hsp70) (Grotewiel et al., 1998) in homozygous $\mathrm{Vol}^{4}$ mutant larvae $\left(\mathrm{Vol}^{4}-\mathrm{T3} / \mathrm{Vol}^{4}-\mathrm{T3}\right)$. $\mathrm{Vol}^{4}-\mathrm{T3}$ larvae receiving multiple heat-shock treatments (see Materials and Methods) display noticeably improved growth and larger size, robust movement, and improved viability compared to $\mathrm{Vol}^{4}$ animals, with a subset of animals rescued to adult viability. Basal EJC amplitude in $0.2 \mathrm{~mm} \mathrm{Ca}^{2+}$ $\left(\mathrm{Vol}^{4}-\mathrm{T} 3+\mathrm{HS} ; 11.4 \pm 1.2 \mathrm{nA} ; n=15\right)$ is significantly reduced $(p<$ 0.002 ) from the $\mathrm{Vol}^{4}$ mutant level and not different from heat- 

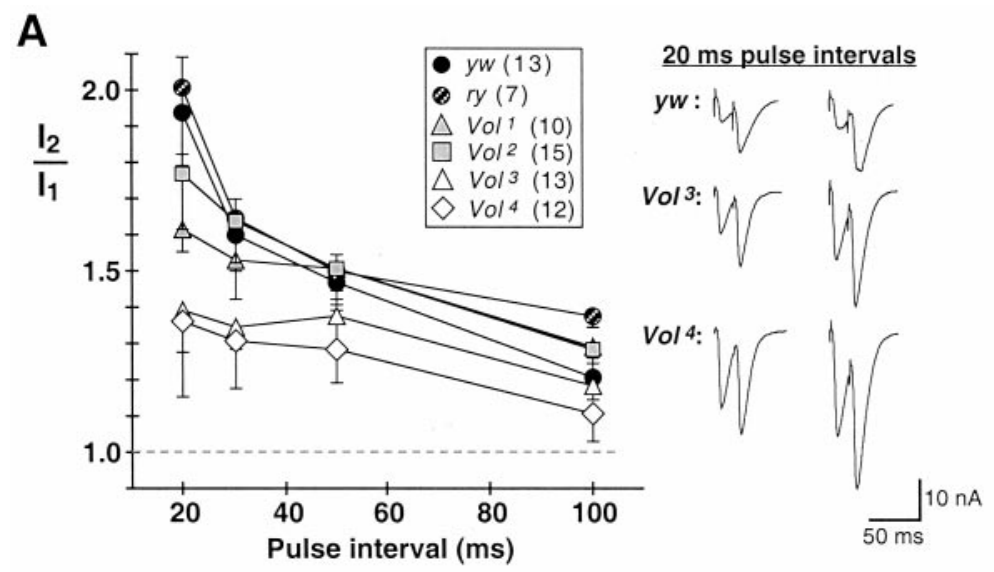

Figure 5. Short-term forms of synaptic facilitation are greatly impaired at lethal $\mathrm{Vol}$ mutant NMJs. Short-term facilitation was evoked in $0.2 \mathrm{mM} \mathrm{Ca}^{2+}$ with paired stimuli $(20-100 \mathrm{msec}$ intervals) and short trains (20 stimuli) at $2-20 \mathrm{~Hz}$. A, PPF. Right, Traces show averages of 5-10 responses to paired stimuli delivered at $20 \mathrm{msec}$ intervals. Examples are shown for two larvae each for control $(y w$, top $)$ and lethal $V o l$ mutant alleles $\left(\mathrm{Vol}^{3}\right.$, middle; $\mathrm{Vol}^{4}$, bottom $)$. Left, Mean PPF ratio $\left(I_{2} / I_{1}\right)$ is plotted for each stimulus interval. For each stimulus interval, $5-10$ responses (separated by $5 \mathrm{sec}$ rest) were averaged. $I_{2} / I_{1}$ is defined as the ratio: mean amplitude of response 2/mean amplitude of response $1 . I_{2}$ peak amplitudes were determined relative to a baseline value immediately preceding the second EJC. Of the viable mutant alleles, Vol ${ }^{2}$ PPF (shaded squares) is indistinguishable from control, whereas $\mathrm{Vol}^{1}$ (shaded triangles) exhibits reduced PPF at the briefest interval $(20 \mathrm{msec})$. Both $\mathrm{Vol}^{3}$ and $\mathrm{Vol}^{4}$ lethal alleles (open symbols) exhibit strongly impaired PPF at 20-30 msec intervals, at which facilitation is normally greatest. Number of larvae for each genotype is indicated in legends. B, STF. Right, Representative responses to $20 \mathrm{~Hz}$ stimulation trains. The first 10 consecutive EJCs are shown (response number indicated above traces), with the average of the last 10 of 20 responses in the train shown in the rightmost traces (average, 11-20). STF at each frequency was defined as the average amplitude of responses 11-20, normalized to mean EJC amplitude at the basal stimulation frequency $(0.5 \mathrm{~Hz})$. Stimulus trains were separated by $10-20 \mathrm{sec}$ rest. EJC amplitude rapidly facilitates by several-fold at control $y w$ or ry NMJs $(y w, t o p)$. $\mathrm{Vol}^{3}$ and $\mathrm{Vol}^{4}$ mutant NMJs (middle and bottom traces) have greater initial EJC amplitudes and weaker facilitation in response $20 \mathrm{~Hz}$ stimuli; in some cases facilitation is absent or replaced with depression ( $\mathrm{Vol}^{4}$, bottom traces). Left, Mean STF at $2-20 \mathrm{~Hz}$ stimulation is plotted for each genotype. Vol $^{2}$ NMJs (shaded squares) have nearly normal STF, whereas $\mathrm{Vol}^{1}$ (shaded triangles), $\mathrm{Vol}^{3}$ (open triangles), and $\mathrm{Vol}^{4}$ (open diamonds) genotypes, respectively, exhibit progressively weaker STF. In particular, $\mathrm{Vol}^{4}$ has on average no STF at $2-5 \mathrm{~Hz}$ stimulation, and STF reduced to $\sim 20 \%$ of control levels at $20 \mathrm{~Hz}$

B

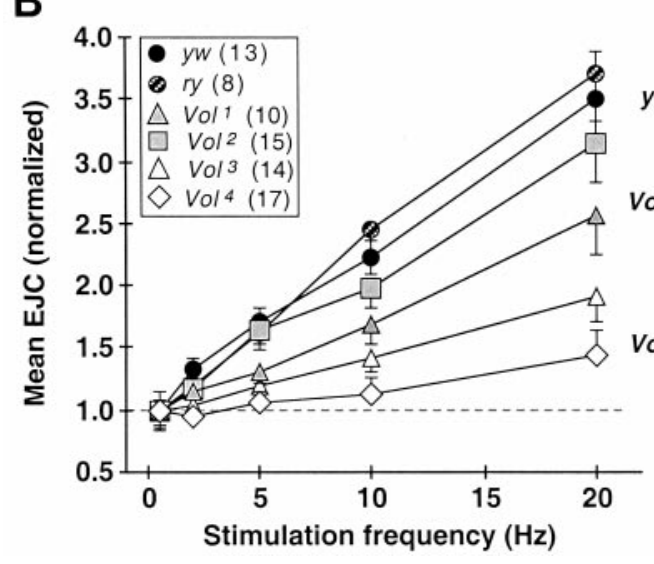

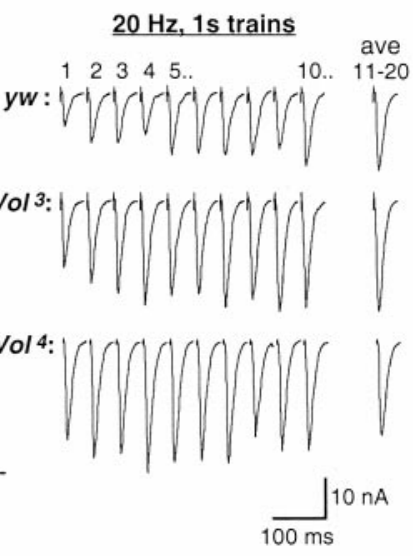

shocked controls ( $y w+\mathrm{HS} ; 9.4 \pm 1.0 \mathrm{nA} ; n=6$ ) (Fig. 7A). Frequency-dependent STF in heat-shocked $\mathrm{Vol}^{4}-\mathrm{T3}$ larvae is dramatically improved and rescued essentially to untreated control levels (Fig. 7B). Likewise, in heat-shocked $\mathrm{Vol}^{4}-\mathrm{T3}$ larvae both augmentation to prolonged $5 \mathrm{~Hz}$ stimulation and PTP are dramatically strengthened compared to $\mathrm{Nol}^{4}$ mutants and rescued to levels comparable to those observed in heat-shocked controls. These results demonstrate that all of the functional transmission defects observed in lethal $\mathrm{Vol}$ mutants, including synaptic plasticity defects, can be strongly rescued through transgenic expression of the normal VOL protein.

\section{Replication of Volado mutant transmission phenotype with an RGD integrin inhibitory peptide}

Integrin-ligand interactions formed over a comparatively brief period of $\sim 20$ min have been implicated in long-term changes in synaptic efficacy (Staubli et al., 1998). Because the altered synaptic transmission amplitudes and impaired plasticity in Volado mutants are manifested after constitutively reducing or eliminating developmental VOL expression, we asked whether acutely inhibiting integrin function at the Drosophila NMJ results in altered transmission resembling the Volado mutant transmission phenotypes.

Control yw larval preparations were incubated for $20 \mathrm{~min}$ in 0.2 $\mathrm{mM} \mathrm{Ca}^{2+}$ saline containing the GRGDSP peptide (RGD; $0.2 \mathrm{~mm}$ ), which interferes with integrin binding to ECM ligands containing the RGD consensus sequence, or a noninhibitory GRADSP control peptide (RAD; 0.2 mM) (Chen and Grinnell, 1995, 1997; Bahr et al., 1997; Stark et al., 1997; Staubli et al., 1998; Graner et al., 1998; Baneres et al., 1998). We subsequently recorded EJCs in 0.2 $\mathrm{mM} \mathrm{Ca}{ }^{2+}$ in the continued presence of either RGD or RAD peptide, at exposure times ranging from 20 to $90 \mathrm{~min}$ (Fig. 7). RAD-treated controls show no effect and have stable EJC amplitudes $(7.7 \pm 2.4 \mathrm{nA}$ overall, mean $\pm \mathrm{SD} ; n=15)$ for $>1 \mathrm{hr}$. In contrast, RGD-treated larvae have elevated EJC amplitudes at initial recording time points $(13.1 \pm 8.8 \mathrm{nA}, 20-25 \mathrm{~min} ; n=7)$, and exhibit a further time-dependent increase in EJC amplitude by more than twofold (Fig. 7A,B). Although NMJs were continuously stimulated at low basal frequencies $(0.2-0.5 \mathrm{~Hz})$, there appeared to be a synergistic effect of combined activity and RGD exposure on transmission. EJC amplitudes after 20-30 min recording in RGD were typically greater than those recorded initially in experiments begun at later exposure times (Fig. 7B). Transmission amplitudes after 30-60 min RGD exposure are comparable (20-40 nA) to those recorded in untreated $\mathrm{Vol}^{3}$ and $\mathrm{Vol}^{4}$ mutant larvae, and are twofold to threefold larger than for RAD controls at exposure times $\geq 30 \mathrm{~min}(p<0.05$; Fig. $7 C)$. In addition, after prolonged RGD exposure relative STF in response to $10-20 \mathrm{~Hz}$ (Fig. $7 A$, bottom traces) or paired pulse stimuli (data not shown) is significantly reduced compared to RAD-treated controls, an effect resembling Volado mutant short-term plasticity defects.

$\mathrm{Vol}^{4}$ mutants exposed to $0.2 \mathrm{~mm}$ RGD have initial EJC amplitudes after 20-25 min exposure $(17.6 \pm 4.0 \mathrm{nA}$, mean $\pm \mathrm{SD} ; n=$ 4) comparable to those recorded from untreated $\mathrm{Vol}^{4}$ larvae $(20.7 \pm 10.8 \mathrm{nA} ; n=28)$ in $0.2 \mathrm{mM} \mathrm{Ca}^{2+}$ (Fig. $8 B, C$; compare to Fig. $4 B) . \mathrm{Vol}^{4} \mathrm{EJC}$ amplitude also increases significantly over the course of $>1$ hr total RGD exposure $(30.8 \pm 11.1 \mathrm{nA},>60 \mathrm{~min}$, $n=4$ vs amplitude at $20-25 \min , p<0.02$, Mann-Whitney $U$ test); however, the relative transmission increase $(75 \%)$ is less than observed for RGD-treated $y w$ larvae over a similar time period. The RGD-dependent transmission changes at normal NMJs strongly support a role for synaptic integrins, including VOL, in the modulation of transmission efficacy.

\section{DISCUSSION}

Integrins have only recently been shown to be localized to adult learning centers, including the mammalian hippocampus and Drosophila mushroom bodies (Einheber et al., 1996; Grotewiel et al., 
A
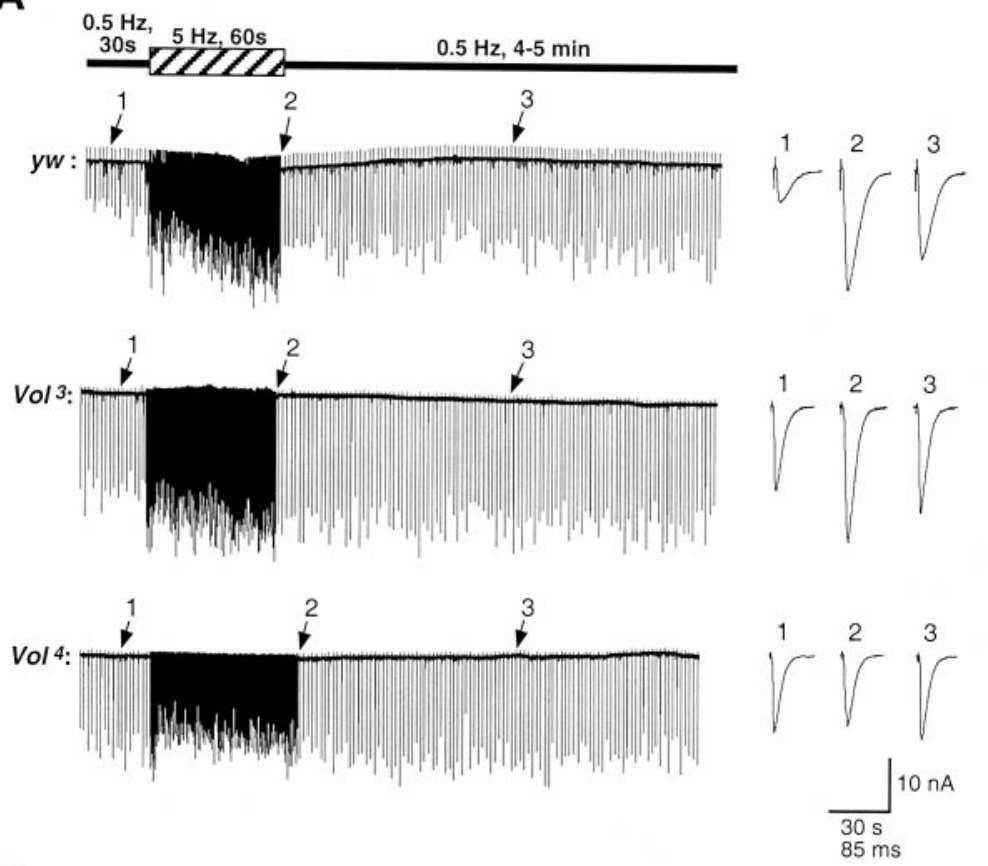

B

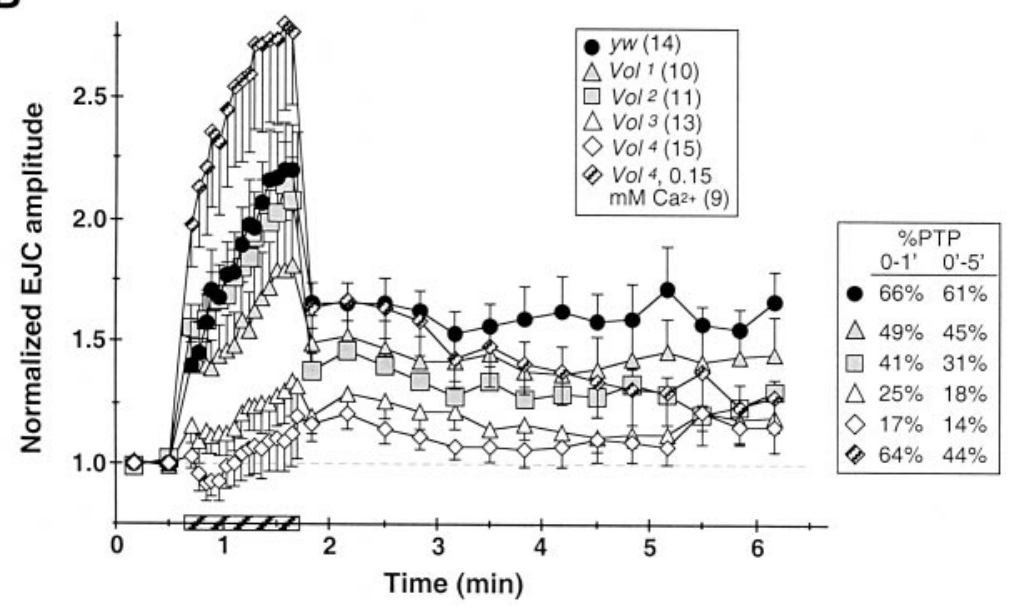

Figure 6. Synaptic augmentation and PTP are greatly impaired at lethal $\mathrm{Vol}$ mutant NMJs. $A$, Representative recordings from $y w$ control (top), $\mathrm{Vol}^{3}$ (middle), and $\mathrm{Vol}^{4}$ mutant (bottom) NMJs in $0.2 \mathrm{~mm} \mathrm{Ca}^{2+}$. Synaptic augmentation was induced by a prolonged $(60 \mathrm{sec})$ tetanic stimulation at $5 \mathrm{~Hz}$ (hatched bar). PTP was assayed for $4-5 \mathrm{~min}$ after termination of the tetanus, at the initial basal stimulation frequency of $0.5 \mathrm{~Hz}$. Traces at left show portions of continuous recordings. EJCs shown at right in expanded time scale are taken from the corresponding continuous records during the initial control period (1), near the end of the tetanus (2), and $\sim 100 \mathrm{sec}$ after tetanus (3) (arrows). Calibration: $10 \mathrm{nA}, 30 \mathrm{sec}$ (continuous traces), and $85 \mathrm{msec}$ (EJCs). B, Synaptic augmentation and PTP, normalized to mean initial EJC amplitude for each larva, are summarized for $y w$ control (solid circles), viable Vol (shaded symbols), and lethal Vol mutant genotypes (open symbols). Each point plots the mean normalized amplitude for 20 consecutive EJCs during the tetanus period (hatched bar) and for 10 consecutive EJCs after tetanus. Control NMJs exhibit rapid initial facilitation, followed by a gradual augmentation of EJC amplitude throughout the 1 min tetanus. In control larvae, potentiation of $66 \%$ over pretetanus amplitude is observed during the initial minute after tetanus $\left(0-1^{\prime}\right)$ and is sustained throughout the $5 \mathrm{~min}$ post-tetanus period $\left(61 \%, 0-5^{\prime}\right.$; see legend to right of plot). PTP for $\mathrm{Vol}^{1}$ and $\mathrm{Vol}^{2}$ alleles is reduced to 50-70\% of control levels. Both $\mathrm{Vol}^{3}$ and $\mathrm{Vol}^{4}$ alleles exhibit strongly reduced augmentation and PTP, particularly the $\mathrm{Vol}^{4}$ allele, which sometimes undergoes depression during tetanic stimulation (note bottom trace in $A$ ) and exhibits overall PTP of only $14 \%$. Rapid facilitation and augmentation is dramatically increased in $\mathrm{Nol}^{4}$ larvae by further reduction of external $\mathrm{Ca}^{2+}$ to $0.15 \mathrm{~mm}$ (hatched diamonds), and initial PTP is restored to the level exhibited by control larvae in $0.2 \mathrm{mM} \mathrm{Ca}^{2+}$; however, the late component of $\mathrm{Vol}^{4}$ PTP (3-5 min) remains decreased relative to control levels. $n \geq 9$ larvae for each genotype.
1998; Pinkstaff et al., 1999). In the hippocampus, inhibiting integrin binding to ligands containing the consensus Arg-Gly-Asp sequence within $\sim 20$ min of LTP induction blocks the subsequent consolidation of LTP (Staubli et al., 1998). This time period ( $20 \mathrm{~min})$ is similar to that during which both LTP and early memories are easily disrupted (Staubli et al., 1998) and to the early component of memory (3-15 min) specifically affected in Volado mutants (Grotewiel et al., 1998), suggesting that integrin activation and signaling act over a course of a few minutes to stabilize these processes. The rescue of mutant STM defects by transgenic Volado expression $3 \mathrm{hr}$ before training demonstrates that the presence of VOL during an interval including the learning period is sufficient for normal memory formation (Grotewiel et al., 1998). The memory requirement of Volado prompted us to examine its synaptic role, particularly in functional modulation processes related to those thought to underlie learning and memory. Our results complement these recent cellular and behavioral studies and demonstrate a role for the VOL $\alpha$-integrin in regulating synaptic morphology, functional transmission, and activity-dependent plasticity.

\section{Volado synaptic expression and localization}

VOL protein is present at low levels throughout most larval synaptic terminals in fixed preparations. In contrast, staining is strongly localized to a limited and variable subpopulation of central and peripheral synapses. Localized punctate VOL expression is present extensively in the CNS neuropil, contained within the broader expression domains of the constitutive presynaptic proteins Synaptotagmin (Syt) and Synaptobrevin (Syb). When transgenically expressed in a neuronal subset [using the gal4 (4G) driver], Syt-GFP and Syb-GFP are observed to be concentrated in extensive puncta and varicosities resembling VOL-localized expression, strongly supporting the conclusion that VOL is indeed concentrated at central synaptic boutons. Likewise, at the NMJ localized VOL expression is observed at all classes of terminals and at all morphological classes of synaptic boutons. Thus, VOL is clearly expressed in a variable population of central and peripheral synaptic boutons.

There are several alternative ways to interpret the intriguing and unusual pattern of synaptic VOL expression. First, VOL may be present only transiently, may be restricted to an extremely limited population of synapses, or both. However, the significant morphological and functional phenotypes exhibited at mutant NMJs are inconsistent with VOL functioning only at a limited subset of boutons or synapses. A second hypothesis that is consistent with the morphological and physiological data is that VOL is expressed at most or all NMJs, but it is concentrated at detectable levels at a subset of terminals and in a variable number of boutons at a given 
A

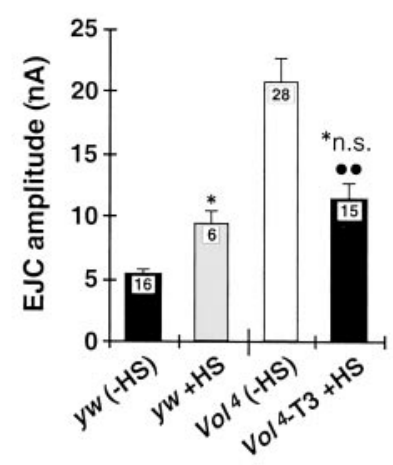

B

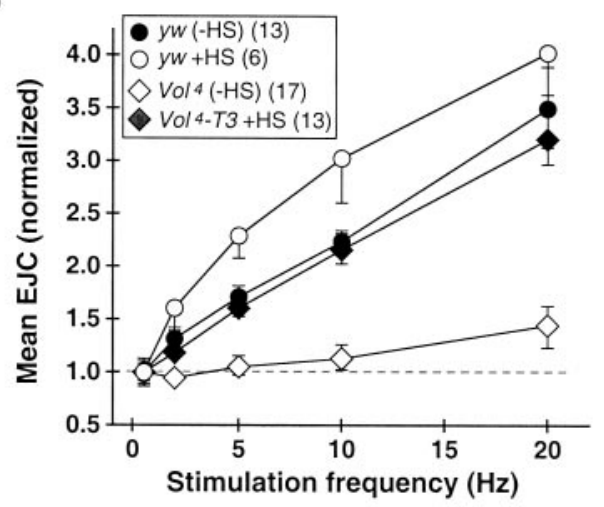

C

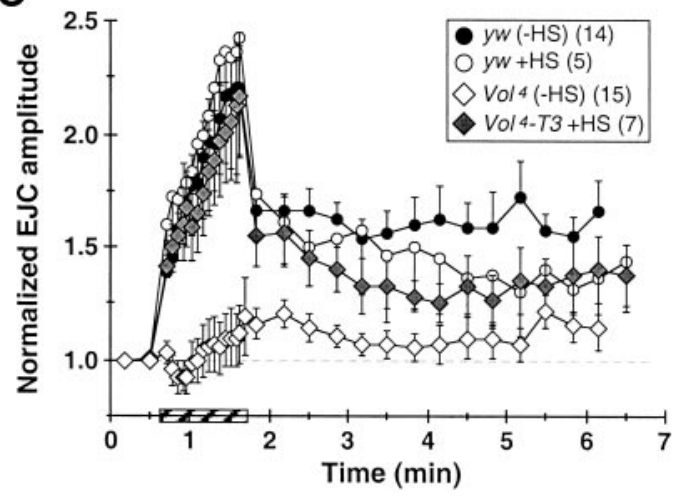

Figure 7. Conditional Volado expression in $\mathrm{Vol}^{4}$ mutant larvae rescues overtransmission phenotype and synaptic plasticity defects. Volado expression in $\mathrm{Vol}^{4}$ mutant larvae $\left(\mathrm{Vol}^{4}-\mathrm{T3} / \mathrm{Vol}^{4}-\mathrm{T3}\right)$ was heat-shock (HS)-induced $\left(30 \mathrm{~min}, 37^{\circ} \mathrm{C}\right)$, using multiple HS spaced over either $4 \mathrm{~d}$ development or over $36 \mathrm{hr}$ before recording (see Materials and Methods). A, HS significantly reduces elevated EJC amplitude at $\mathrm{Vol}^{4} \mathrm{NMJ}\left(\mathrm{Vol}^{4}-\mathrm{T} 3+\mathrm{HS}\right.$, right bar vs $\left.\mathrm{Vol}^{4}(-\mathrm{HS}) ; p<0.005\right)$ to the level of heat-shocked control larvae $\left(y w+\mathrm{HS}\right.$; no significant difference vs $\left.\mathrm{Vol}^{4}-\mathrm{T3}+\mathrm{HS}\right)$. EJC amplitude for $y w$ $+\mathrm{HS}$ is increased by $80 \%$ over untreated $y w$ larvae. EJC data for $y w$ and $\mathrm{Vol}^{4}$ are the same as in Figure $4 B$. B. HS restores $\mathrm{Vol}^{4}$ short-term facilitation ( $\mathrm{Vol}^{4}-\mathrm{T3}+\mathrm{HS}$; shaded diamonds) to untreated control levels (yw (-HS)). HS also slightly improves STF at intermediate stimulation frequencies in $y w$ larvae ( $y w+\mathrm{HS}$; shaded circles). Data for $y w$ and $\mathrm{Vol}^{4}$ is the same as in Figure $5 B$. C, HS largely restores $\mathrm{Vol}^{4}$ synaptic augmentation and PTP to levels of heat-shocked controls. Data for $y w$ and $\mathrm{Vol}^{4}$ is the same as in Figure $6 B$.

time. One possibility is that VOL is transiently concentrated to distinct boutons in response to an inducing signal. Although we currently have no direct evidence for such dynamic relocalization, it is consistent with previous integrin studies and all of the data presented in this study. A third possibility, which we cannot presently exclude, is that an unknown mechanism that causes epitope modification or masking of the antibody recognition site creates variability in the level of VOL immunostaining. The more extensive localization of the protein to the central neuropil likely reflects the high density of synaptic connections in this region or differences in the dynamic regulation of localized expression by activity or other mechanisms. However, the observation of VOL expression in variable subsets of synaptic boutons is consistent in both central and peripheral synaptic terminals.

\section{Volado regulates morphological growth, functional transmission, and activity-dependent plasticity at the NMJ}

Vol mutant NMJs exhibit moderate but significant overgrowth at multiple terminal types, suggesting VOL has a broad developmental role in limiting morphological synaptic growth. The altered evoked transmission amplitudes and defective plasticity properties in $\mathrm{Vol}$ mutants, however, indicate that VOL has an additional functional role regulating synaptic transmission and activitydependent synaptic modulation. The severity of transmission phenotypes among both viable and lethal mutant $\left(\mathrm{Vol}^{1}, \mathrm{Vol}^{3}, \mathrm{Vol}^{4}\right)$ animals again strongly suggests that VOL directly regulates function throughout the synapse, or alternatively, is able to indirectly influence the function of a broader area via some signal transduction pathway.

Both viable $\left(\mathrm{Vol}^{1}\right)$ and lethal $\mathrm{Vol}$ mutant alleles $\left(\mathrm{Vol}^{3}, \mathrm{Vol}^{4}\right)$ display abnormally elevated evoked transmission amplitudes, altered $\mathrm{Ca}^{2+}$ dependence of transmission, and severe defects in short-term plasticity at the NMJ. In the viable $\mathrm{Vol}^{2}$ memory mutant, basal transmission amplitude and short-term plasticity are essentially normal. However, all alleles, including $\mathrm{Vol}^{2}$, display significantly reduced PTP, indicating that mutant plasticity defects do not result simply from elevated basal transmission levels. It should be stated clearly that these forms of synaptic plasticity at the NMJ, although highly conserved at central synapses, cannot be directly correlated to particular phases of behavioral learning or memory. The Vol mutant defects are consistent, however, with an inability to rapidly modulate transmission in response to increased presynaptic activity and to maintain changes in transmission strength in the absence of maintained input, plasticity properties that are likely to be relevant for memory formation.

Conditional expression of the $\mathrm{Vol}$-s isoform in the lethal $\mathrm{Vol}^{4}$ allele dramatically rescues transmission amplitude, STF, augmentation, and PTP to levels near or equal to those at control NMJs. Similar results were obtained by driving VOL expression over most of larval development, or over $\sim 36 \mathrm{hr}$ in late larval stages. The subtle differences in the completeness of rescue of individual transmission properties may indicate different sensitivities to the timing and level of VOL expression relative to normal, or different functions for the Vol-l and Vol-s isoforms. These results strongly support a direct role for VOL in synaptic transmission and plasticity mechanisms. Whereas the pharmacological perturbation with the RGD integrin inhibitory peptide lacks the specificity of the Volado genetic knock-out and transgenic rescue approach, it offers the only available means of assessing the consequence of acutely disrupting normal synaptic integrin function. At wild-type NMJs, exposure to RGD rapidly (within 30-60 min) leads to increased transmission amplitude and loss of presynaptic short-term facilitation. The similarity of the RGD-dependent modulation of transmission to the Vol mutant phenotype suggests VOL may mediate this rapid modulation. Consistent with this possibility, the $\alpha$ VOL sequence includes three consensus extracellular $\mathrm{Ca}^{2+}$-binding domains (Grotewiel et al., 1998) conserved in integrin RGD receptors (Baneres et al., 1998). However, the ligand interactions of VOL are not yet characterized. Our results also indicate that the RGDdependent modulation may be mediated in part by other synaptic integrins. The most likely such candidate is $\alpha \mathrm{PS} 2 / \beta \mathrm{PS}$, which is abundantly localized to type I boutons at the NMJ (Beumer et al., 1999) and has been shown to mediate RGD-dependent cell adhesion in vitro (Graner et al., 1998). These results primarily demonstrate that acutely altering synaptic integrin function in Drosophila, as in vertebrates (Chen and Grinnell, 1995, 1997; Staubli et al., 1998), can rapidly and dramatically modulate transmission efficacy. 
A

RGD

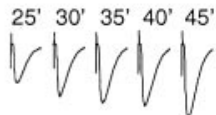

$25^{\prime} 30^{\prime} 35^{\prime} 40^{\prime} 45^{\prime} 50^{\prime} 55^{\prime} \quad 57^{\prime}, 10 \mathrm{~Hz}$

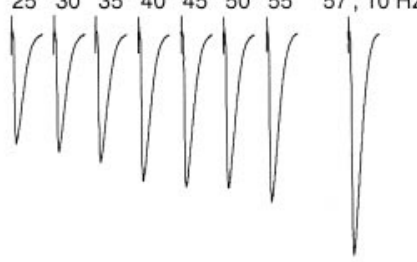

B

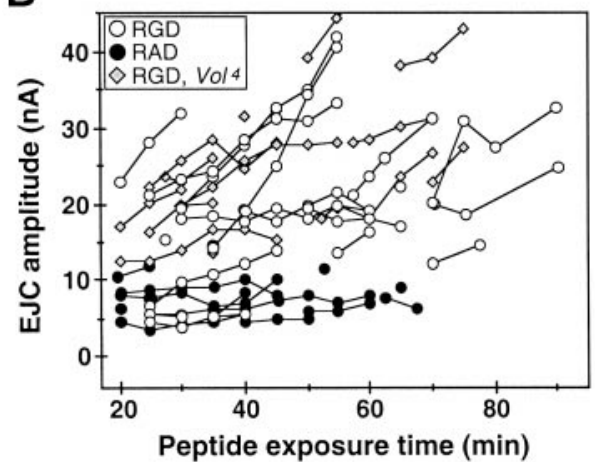

RAD (control)

$20^{\prime} 25^{\prime} 30^{\prime} 35^{\prime} 40^{\prime} 45^{\prime}$ la $\sqrt{1} \sqrt{1}$

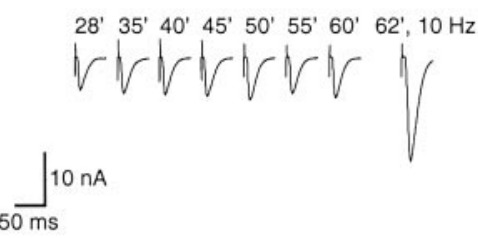

C

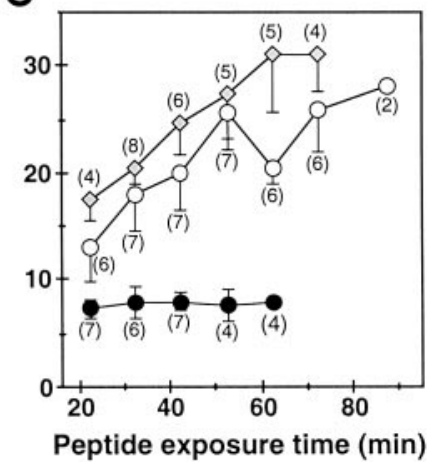

Figure 8. Inhibition of functional integrin interactions at the NMJ phenocopies Volado mutant synaptic transmission. $A$, EJCs (averages of 10 consecutive responses evoked at $0.2-0.5$ $\mathrm{Hz}$ ) recorded in $y w$ larvae in $0.2 \mathrm{mM} \mathrm{Ca}^{2+}$ saline containing the integrin RGD inhibitory peptide $(0.2 \mathrm{mM}$; left $)$ or the noninhibitory control RAD peptide $(0.2 \mathrm{mM}$; right $)$. Dissected preparations were incubated with RGD- or RAD-containing saline for $20 \mathrm{~min}$ before beginning recording; total peptide exposure time (in minutes) is indicated above traces. Each row of traces was recorded from one NMJ. Left, EJCs recorded from RGD-treated NMJs. In bottom example, initial EJC amplitude (25 min RGD) is significantly elevated, and both RGDtreated NMJs exhibit a progressive increase in EJC amplitude over the 20-30 min recording period. After prolonged ( $>1 \mathrm{hr}$ ) RGD exposure, EJC amplitude can usually be further facilitated by $10-20 \mathrm{~Hz}$ stimulation (bottom right trace, $57 \mathrm{~min}, 10$ $\mathrm{Hz}$ stimulation; last 10 of 20 responses are averaged as in Fig. $4 B$ ), but relative STF is significantly weaker than in RADtreated controls $(n=4)$. Right, EJC amplitudes in RADtreated NMJs (right) are comparable to those of untreated $y w$ larvae, remain stable throughout continuous 25-30 min recordings, and exhibit robust facilitation to $10-20 \mathrm{~Hz}$ stimulation after $>1$ hr RAD exposure (bottom right trace, $62 \mathrm{~min}, 10 \mathrm{~Hz}$ stimulation). $B, C$, Time course of RGD-dependent alteration of transmission. $B$, EJC amplitudes recorded in RGD-treated $y w$ control (open circles; $n=18$ ) and $\mathrm{Vol}^{4}$ mutant larvae (shaded diamonds; $n=17$ ) are plotted versus peptide exposure time. Control recordings from RAD-treated $y w$ larvae are plotted in solid circles $(n=15)$. Symbols connected by lines represent continuous recordings from individual larvae. Mean EJC amplitudes (0.2-0.5 Hz stimulation) are plotted at $5 \mathrm{~min}$ intervals, except for several points recorded at intermediate (2.5 min) intervals. Most RGD-treated NMJs in $y w$ larvae have elevated initial EJC amplitudes (20-30 min exposure) relative to RAD-treated controls and exhibit further increased EJC amplitude with increased exposure time and activity. EJC

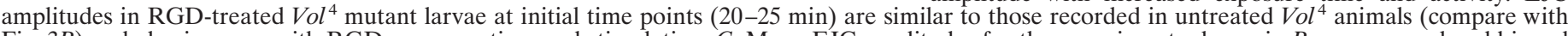

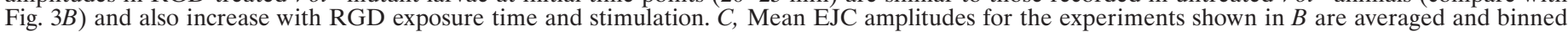

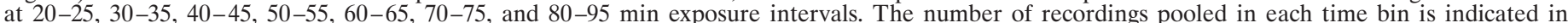

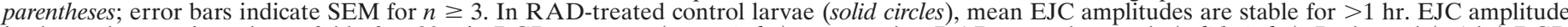

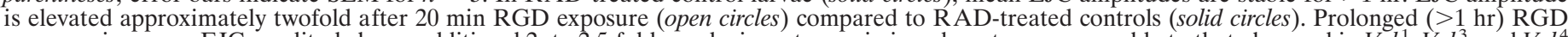

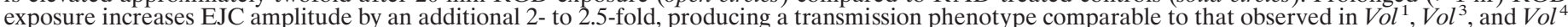

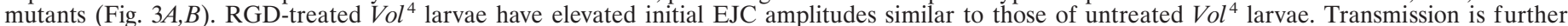
increased by $\sim 75 \%$ with exposure time and activity, suggesting multiple synaptic integrins are disrupted by RGD.

\section{Potential mechanisms for integrin-mediated modulation of synaptic function and memory}

Our results show that integrin interactions at the synapse stabilize basal transmission, mediate rapid (minutes) changes in transmission strength, and are required for normal $\mathrm{Ca}^{2+}-$ and activitydependent forms of plasticity. The cellular mechanisms by which VOL regulates synaptic transmission and memory formation and the significance of its variable pattern of synaptic localization remain to be determined. The richness of known integrin interactions (Hynes, 1992; Clarke and Brugge, 1995; Jones, 1996) suggests multiple potential roles for VOL in synaptic mechanisms (Grotewiel et al., 1998). One possibility is that $\alpha$ VOL, with its $\beta P S$ integrin partner (Stark et al., 1997), is linked to or positioned to interact with the synaptic vesicle fusion machinery. Integrins have recently been reported to be localized to active zones of neuromuscular synapses (Cohen et al., 2000). Such a close relationship with presynaptic $\mathrm{Ca}^{2+}$ channels and the $\mathrm{Ca}^{2+}$-sensitive vesicle fusion machinery could position integrins to directly modulate the probability of transmitter release in response to $\mathrm{Ca}^{2+}$ influx, thereby regulating both evoked release and rapid modulatory processes. Disrupting this relationship in Volado mutants might account for increased EJC amplitudes, reduced $\mathrm{Ca}^{2+}$ dependence of transmission, loss of short-term forms of $\mathrm{Ca}^{2+}$-dependent plasticity, and the rapid phenocopying of similar synaptic defects by the RGD peptide.

For synaptic integrins to contribute to long-term changes in synaptic efficacy, however, interactions with additional cellular signaling pathways would appear necessary. Memory and longterm experimental forms of synaptic plasticity are known to require $\mathrm{Ca}^{2+}$ - and cAMP-dependent signaling (Hawkins et al., 1993; Bailey et al., 1996), and both appear to be accompanied by prolonged functional modulation of transmission properties, and/or the physical stabilization or addition of synaptic connections
(Bailey, 1999; Engert and Bonhoeffer, 1999; Maletic-Savatic et al., 1999; Murase and Schuman, 1999). Dynamic changes in the structure and function of synaptic connections could potentially be regulated by altered integrin adhesion and signaling function, triggered by increased synaptic activity. Localized integrin expression is detected in hippocampal dendritic spines and postsynaptic densities (Einheber et al., 1996), and appearance of new dendritic spines has been documented within minutes after LTP induction (Engert and Bonhoeffer, 1999; Maletic-Savatic et al., 1999), suggesting integrins could be used in formation or stabilization of new synapses or structural changes to existing contacts. Transient changes in cytosolic $\mathrm{Ca}^{2+}$ levels are known to regulate subcellular integrin redistribution and cell morphology (Lawson and Maxfield, 1995; Bixby and Bookman, 1996). It was recently reported that intense synaptic activation stimulates the cellular relocalization and molecular stabilization of another class of cell adhesion and signaling protein, $N$-cadherin, at hippocampal synapses (Tanaka et al., 2000). Increased neuronal activity and synaptic $\mathrm{Ca}^{2+}$ influx may similarly trigger VOL redistribution and concentration in synaptic boutons. We hope to directly examine this possibility in the future by expressing and imaging a Volado-GFP fusion protein in living synaptic terminals.

Several modulatory signaling pathways downstream of activitydependent increases in synaptic $\mathrm{Ca}^{2+}$ could potentially regulate dynamic changes in synaptic integrin localization and adhesion, including the cAMP-, protein kinase $\mathrm{C}$ (PKC)-, and $\mathrm{Ca}^{2+} /$ calmodulin (CaM)-dependent pathways, and calcineurin (Hynes, 1992; Diamond and Springer, 1994; Clarke and Brugge, 1995; Lawson and Maxfield, 1995; Grotewiel et al., 1998). These transduction pathways are implicated in synaptic modulation and memory formation in Drosophila and mammalian systems (Zhong and Wu, 1991; Zhong et al., 1992; Hawkins et al., 1993; Davis et al., 1995; Bailey et al., 1996; Davis, 1996; Dubnau and Tully, 1998). Inte- 
grin-ligand binding can in turn trigger $\mathrm{Ca}^{2+}$ influx and release from intracellular stores (Clarke and Brugge, 1995; Bixby and Bookman, 1996), increased PKC activity (Clarke and Brugge, 1995), and activation of the presynaptic $\mathrm{Ca}^{2+}$-binding protein calreticulin, which interacts dynamically with $\alpha$-integrins to regulate adhesion and transient $\mathrm{Ca}^{2+}$ influx (Dedhar, 1994; Coppolino et al., 1997). Interestingly, calreticulin is increased after long-term sensitization in Aplysia (Kennedy et al., 1992) and has been proposed to modulate gene expression after integrin activation (Dedhar, 1994), suggesting that integrin-mediated forms of long-term plasticity and memory may be associated with new gene expression necessary to stabilize or "cement" transient morphological alterations.

The VOL $\alpha$-integrin, although a new player in synaptic mechanisms underlying memory, thus fits squarely within the established molecular and biochemical framework. Future work will be directed toward dissecting specific cellular mechanisms and molecular pathways through which VOL may interact with the products of other learning genes to contribute to learning and memory processes.

\section{REFERENCES}

Bahr BA, Staubli U, Xiao P, Chun D, Ji ZX, Esteban ET, Lynch G (1997) Arg-Gly-Asp-Ser-selective adhesion and the stabilization of long-term potentiation: pharmacological studies and characterization of a candidate matrix receptor. J Neurosci 17:1320-1329.

Bailey CH (1999) Structural changes and the storage of long-term memory in Aplysia. Can J Physiol Pharmacol 77:738-747.

Bailey CH, Bartsch D, Kandel ER (1996) Toward a molecular definition of long-term memory storage. Proc Natl Acad Sci USA 93:13445-13452.

Baneres JL, Roquet F, Green M, LeCalvez H, Parello J (1998) The cation-binding domain from the $\alpha$ subunit of integrin $\alpha 5 \beta 1$ is a minimal domain for fibronectin recognition. J Biol Chem 273:24744-24753.

Beumer KJ, Rohrbough J, Prokop A, Broadie K (1999) A role for PS integrins in morphological growth and synaptic function at the postembryonic neuromuscular junction of Drosophila. Development 126:5833-5846.

Bixby JL, Bookman RJ (1996) Intracellular mechanisms of axon growth induction by CAMs and integrins: some unresolved issues. Perspect Dev Neurobiol 4:147-156.

Boynton S, Tully T (1992) Latheo, a new gene involved in associative learning and memory in Drosophila melanogaster, identified from P element mutagenesis. Genetics 132:655-672.

Broadie K, Bate M (1993) Development of the embryonic neuromuscular synapse of Drosophila melanogaster. J Neurosci 13 144-166.

Broadie K, Prokop A, Bellen HJ, O'Kane CJ, Schulze KL, Sweeney ST (1995) Syntaxin and synaptobrevin function downstream of vesicle docking in Drosophila. Neuron 15:663-673.

Broadie K, Rushton E, Skoulakis EMC, Davis RL (1997) Leonardo, a Drosophila 14-3-3 protein involved in learning, regulates presynaptic function. Neuron 19:391-402.

Chen B-M, Grinnell A (1995) Integrins and modulation of transmitter release from motor nerve terminals by stretch. Science 269:1578-1580.

Chen B-M, Grinnell A (1997) Kinetics, $\mathrm{Ca}^{2+}$ dependence, and biophysical properties of integrin-mediated mechanical modulation of transmitter release from frog motor nerve terminals. J Neurosci 17:904-916.

Clarke EA, Brugge JS (1995) Integrins and signal transduction pathways: the road taken. Science 268:233-239.

Cohen MW, Hoffstrom BG, DeSimone DW (2000) Active zones on motor nerve terminals contain $\alpha 3 \beta 1$ integrin. J Neurosci 20:4912-4921.

Coppolino MG, Woodside MJ, Demaurex N, Grinstein S, St-Arnaud R, Dedhar S (1997) Calreticulin is essential for integrin-mediated calcium signaling and cell adhesion. Nature 386:843-847.

Davis RL (1996) Physiology and biochemistry of Drosophila learning. Physiol Rev 76:299-317.

Davis RL, Cherry J, Dauwalder B, Han PL, Skoulakis EMC (1995) The cyclic AMP system and Drosophila learning. Mol Cell Biochem 149-150:271-278.

Dedhar S (1994) Novel functions for calreticulin: interactions with inte- grins and modulation of gene expression? Trends Biochem Sci 19:269-271.

Diamond MS, Springer TA (1994) The dynamic regulation of integrin adhesiveness. Curr Biol 4:506-517.

Dubnau J, Tully T (1998) Gene discovery in Drosophila: new insights for learning and memory. Annu Rev Neurosci 21:407-444.

Einheber S, Schnapp LM, Salzer JL, Cappiello ZB, Milner TA (1996) Regional and ultrastructural distribution of the alpha 8 integrin subunit in developing and adult rat brain suggests a role in synaptic function. J Comp Neurol 370:105-134.

Engert F, Bonhoeffer T (1999) Dendritic spine changes associated with hippocampal long-term synaptic plasticity. Nature 399:66-70.

Estes PS, Ho GL, Narayanan R, Ramaswami M (2000) Synaptic localization and restricted diffusion of a Drosophila neuronal synaptobrevingreen fluorescent protein chimera in vivo. J Neurogenet 13:233-255.

FlyBase (2000) The FlyBase database of the Drosophila genome projects and community literature. Nucleic Acids Res 27:85-88. http://flybase.bio.indiana.edu/.

Graner MW, Bunch TA, Baumgartner S, Kershen A, Brower DL (1998) Splice variants of the Drosophila PS2 integrins differentially interact with RGD-containing fragments of the extracellular proteins Tiggrin, Ten-m, and D-Laminin $\alpha 2$. J Biol Chem 273:18235-18241.

Grotewiel MS, Beck CDO, Wu KH, Zhu X-R, Davis RL (1998) Integrinmediated short-term memory in Drosophila. Nature 391:455-460.

Hawkins RD, Kandel ER, Siegelbaum SA (1993) Learning to modulate transmitter release: themes and variations in synaptic plasticity. Annu Rev Neurosci 16:625-665.

Hynes RO (1992) Integrins: versatility, modulation, and signaling in cell adhesion. Cell 69:11-25.

Jan LY, Jan YN (1976) Properties of the larval neuromuscular junction in Drosophila melanogaster. J Physiol (Lond) 262:189-214.

Jones LS (1996) Integrins: possible functions in the adult CNS. Trends Neurosci 19:68-72.

Kennedy TE, Kuhl D, Barzali A, Sweatt JD, Kandel E (1992) Long-term sensitization training in Aplysia leads to an increase in calreticulin, a major presynaptic calcium-binding protein. Neuron 9:1013-1024.

Lawson MA, Maxfield FR (1995) $\mathrm{Ca}^{2+}$ - and calcineurin-dependent recycling of an integrin to the front of migrating neutrophils. Nature 377:75-79.

Maletic-Savatic M, Malinow R, Svoboda K (1999) Rapid dendritic morphogenesis in CA1 hippocampal dendrites induced by synaptic activity. Science 283:1923-1927.

Murase S, Schuman EM (1999) The role of cell adhesion molecules in synaptic plasticity and memory. Curr Opin Cell Biol 11:549-553.

Nusslein-Volhard C, Wieschaus E, Kluding H (1984) Mutations affecting the pattern of the larval cuticle in Drosophila melanogaster. I. Zygotic loci on the second chromosome. Wilhelm Roux's Arch Dev Biol 193:267-282.

Pinkstaff JK, Detterich J, Lynch G, Gall C (1999) Integrin subunit gene expression is regionally differentiated in adult brain. $J$ Neurosci 19:1541-1546.

Rohrbough J, Pinto S, Mihalek RM, Tully T, Broadie K (1999) latheo, a Drosophila gene involved in learning, regulates functional synaptic plasticity. Neuron 23:55-70.

Skoulakis EMC, Davis RL (1996) Olfactory learning deficits in mutants for leonardo, a Drosophila gene encoding a 14-3-3 protein. Neuron 17:931-944.

Stark KA, Yee GH, Roote CE, Williams EL, Zusman S, Hynes RO (1997) A novel $\alpha$ integrin subunit associates with $\beta$ PS and functions in tissue morphogenesis and movement during Drosophila development. Development 124:4583-4594.

Staubli U, Chun D, Lynch G (1998) Time-dependent reversal of long-term potentiation by an integrin antagonist. J Neurosci 18:3460-3469.

Tanaka H, Shan W, Phillips GR, Arndt K, Bozdagi O, Shapiro L, Huntley GW, Benson DL, Colman DR (2000) Molecular modification of N-cadherin in response to synaptic activity. Neuron 25:93-107.

Wang J, Renger JJ, Griffith LC, Greenspan RJ, Wu C-F (1994) Comcomitant alterations of physiological and developmental plasticity in Drosophila CaM Kinase II-inhibited synapses. Neuron 13:1373-1384.

Zhong Y, Wu C-F (1991) Altered synaptic plasticity in Drosophila memory mutants with a defective cyclic AMP cascade. Science 251:198-201.

Zhong Y, Budnik V, Wu C-F (1992) Synaptic plasticity in Drosophila memory and hyperexcitable mutants: role of cAMP cascade. J Neurosci 12:644-651. 